Bolm Inst. oceanogr., S Paulo, 25:221-280, 1976

\title{
VARIAÇÕES EM ESCALA MÉDIA DA TEMPERATURA E DA SALINIDADE DO MAR NA REGIÃO ENTRE A BAIA DE GUANABARA E CABO FRIO (17/08 A 26/08/1971)*
}

\author{
YOSHIMINE IKEDA
}

Instituto Oceanográfico da Universidade de São Paulo

\section{SYNOPSIS}

It should be pointed out that this paper reports observations conducted ininterruptdly during a 10 day period on anomalous distribution of physical properties of sea water. The experimental results obtained on the coastal region west off Cabo Frio (RJ), during the mentioned period showed the dominance of advectives and difusal processes causing changes in the distribution of temperature and salinity on sea surface layer. The anomaly recorded may be indicated by clouds of the "cumulus" type formed by penetrating convection, a fact which may be confirmed by comparing photographic data obtained by ERTS satellite.

\section{INTRODUÇÃO}

Tem por objetivo o presente trabalho, estudar as distribuições das propriedades oceanográficas na região de Cabo Frio, observados na escala espacial (10-100 km) e temporal (dias), classificada como escala média (Roll, 1974), e a indicação da influência do vento induzindo as anomalias observadas na temperatura e na salinidade da superfície do mar, bem como aquelas verificadas em profundidade e que são analisadas nas secções verticais.

* . Dissertação de mestrado apresentada à Comissão de Pós-Graduação do Instituto Oceanográfico da Universidade de São Paulo.

PUBL. NO 381 DO INST. OCEAN. DA USP. 
0 cruzeiro oceanográfico foi realizado no mês de agosto de 1971, compreendendo as latitudes de $23^{\circ} 00^{\prime}$ e $23^{\circ} 30^{\prime} \mathrm{s}$ e longitudes de $41^{\circ} 50^{\prime}$ e $44^{\circ} 00^{\prime} \mathrm{W}$. Além das medições contínuas de temperatura e de salinidade com o termosalinógrafo, foram efetuadas duas redes de estações oceanogräficas (Fig. 1).

Os motivos que levaram à realização deste trabalho foram:

1 - participação do autor, na instalação e teste do termosalinógrafo, no planejamento e no cruzeiro oceanográfico;

2 - disponibilidade de dados "quase-sinóticos" inéditos para a região, cuja análise preliminar foi apresentada por Ikeda et al. (1971);

3 - vārios trabalhos jā realizados na região, embora não em escala média;

4 - importância do estudo dessas anomalias, no que se refere à identificação de regiões de ressurgência, e o estudo dos seus efeitos biológicos.

Defant (1961) ao apresentar as distribuições de temperatura, salinidade e densidade nos oceanos, menciona o atlas de Böhnecke (1936) como a representação mais compreensiva sobre as variações (mensais para a temperatura e trimestrais para a salinidade e densidade) dessas propriedades na superfície do Oceano Atlântico. Para a elaboração desse atlas, Böhnecke utilizou-se das informações obtidas durante a expedição do "Meteor" (1925-27) e também de todas as informações disponíveis de temperatura e de salinidade observadas no Oceano Atlântico.

Com relação à região em estudo (Fig. 1), esse atlas contēm os primeiros resultados das condições hidrogräficas de Cabo Frio, podendo-se tirar dele os seguintes valores extremos de variação da temperatura $(T)$, da salinidade (S) e da densidade $\left(\sigma_{\mathrm{T}}\right)$ :

$$
\begin{array}{llll}
\text { agosto } & \left(\mathrm{T}<19,0^{\circ} \mathrm{C}\right) & \text { e março } & \left(\mathrm{T} \cong 25,0^{\circ} \mathrm{C}\right) \\
\text { junho/agosto } & \left(\mathrm{S}<35,5^{\circ} / \mathrm{oo}\right) & \text { e dezembro/fevereiro } & \left(\mathrm{S} \cong 36,0^{\circ} / \mathrm{oo}\right) \\
\text { março/maio } & \left(\sigma_{\mathrm{T}}=24,2\right) & \text { e junho/agosto } & \left(\sigma_{\mathrm{T}}>25,5\right)
\end{array}
$$




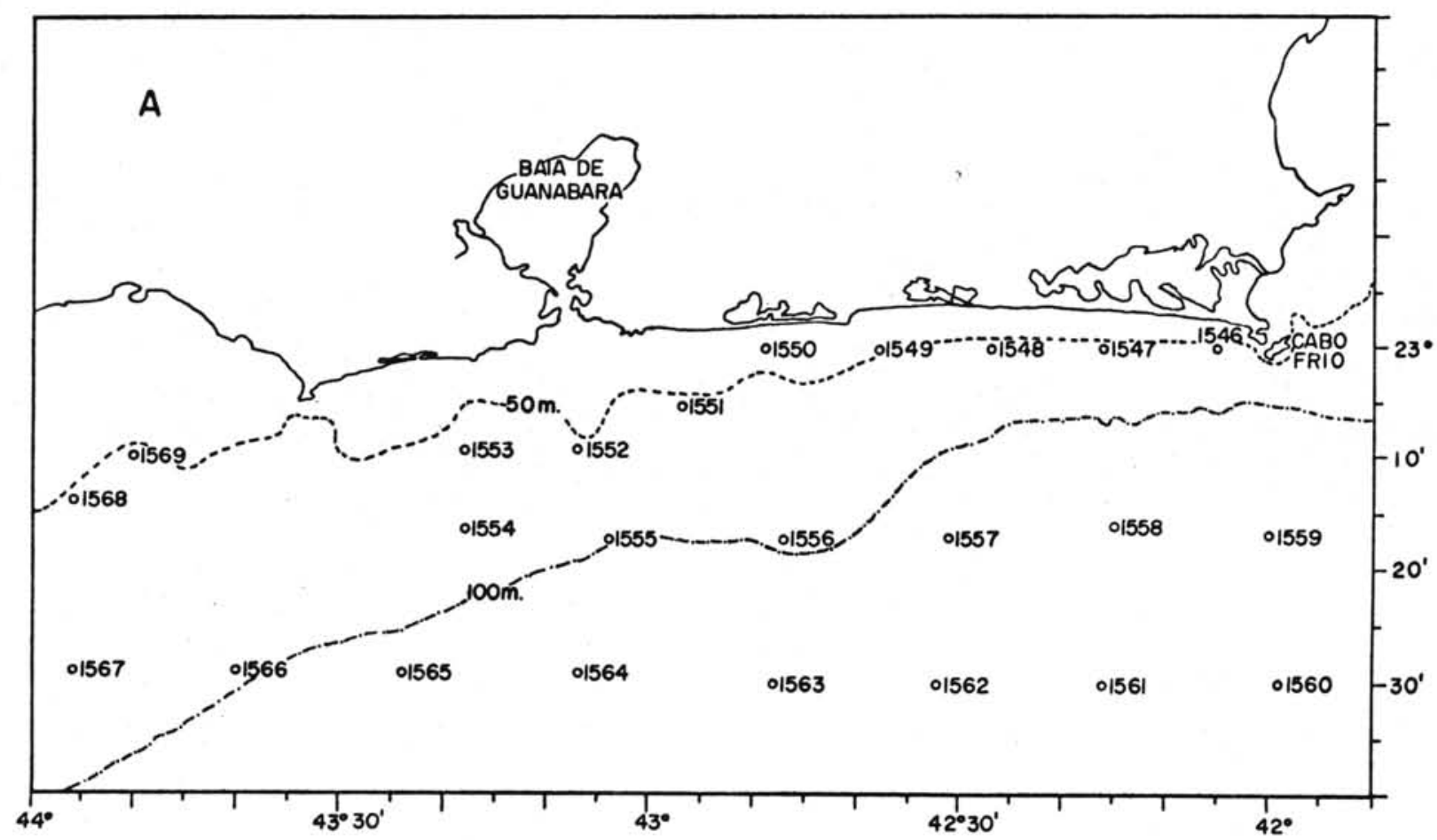

Fig. 1a - Posição das estações hidrogräficas ocupadas no período de 21/08/71 a 23/08/71.

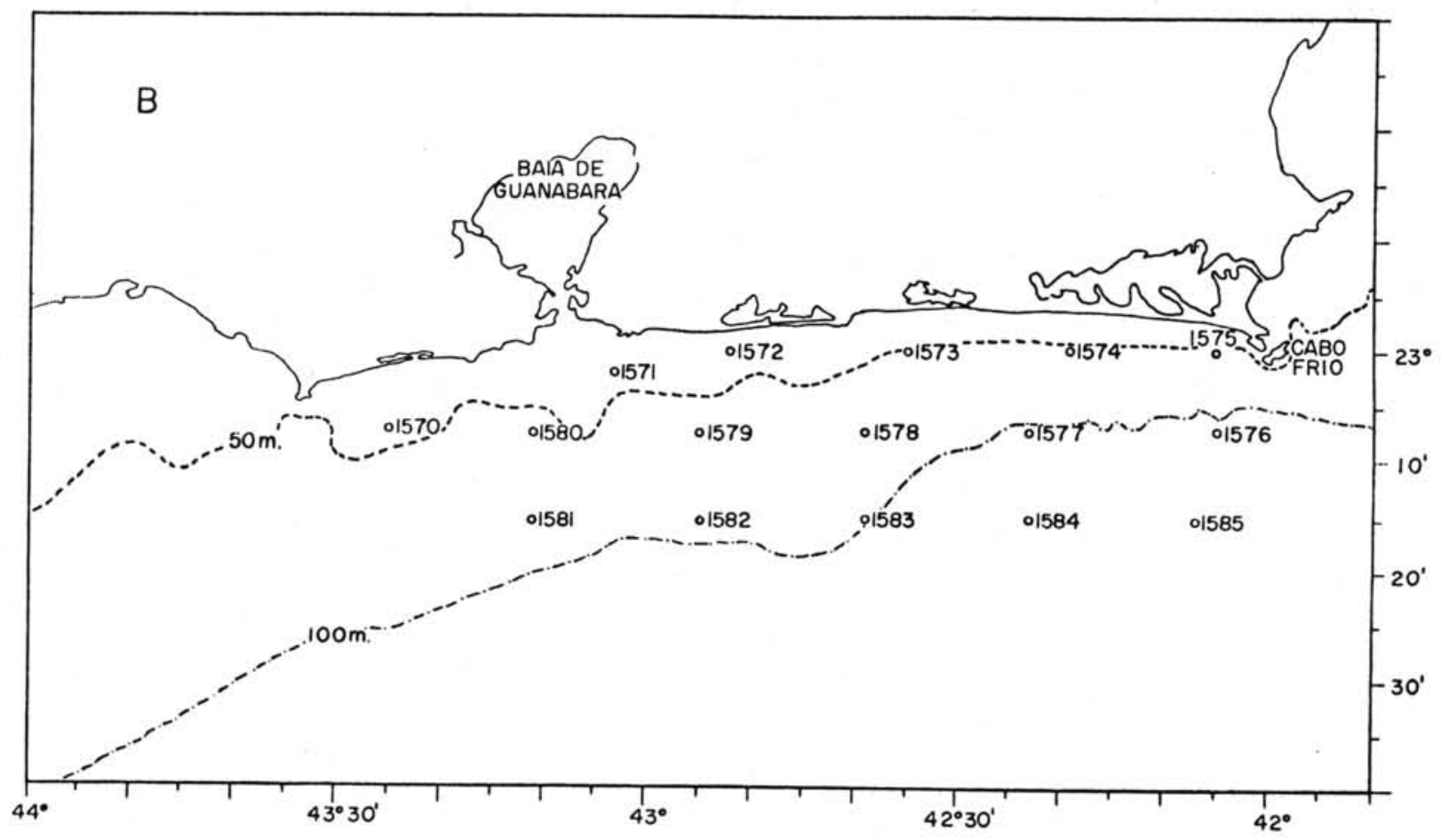

Fig. $1 b$ - Posição das estações hidrogräficas ocupadas no período de 23/08/71 a $24 / 08 / 71$. 
Uma vez que as observações das propriedades oceanogräficas, na superfície, apresentadas por Böhnecke ( $o p$. cit.) foram feitas em escala grande, posteriormente, outros trabalhos foram realizados com maior número de estações oceanogräficas, para complementar o trabalho na região de Cabo Frio.

Allard (1955), analisando os dados de temperatura e de ventos da Companhia Nacional de Alcalis, Cabo Frio, do período de agosto-setembro de 1949, observou uma correlação muito interessante entre a direção do vento e as anomalias de temperatura: quando a temperatura da água abaixa, a direção do vento é $\mathrm{NE}$ quando ela atinge o seu mínimo, e quando a temperatura começa a se elevar, o vento jā mudou de direção passando a soprar de SW; o ar se torna mais úmido. Comparando este período de observações com outros, o autor conclui ainda que este período fôra o mais característico para tais anomalias em Cabo Frio.

Mascarenhas et al. (1971a) mencionam que Emílsson em 1956, constatou a ocorrência do fenômeno da ressurgência em Cabo Frio, através de um forte gradiente horizontal de temperatura na superfície do mar, e que, posteriormente, a Marinha Brasileira, integrante do Programa IGY-1957 (International Geophysical Year) observou o mesmo fenômeno ao sul de Cabo Frio e também na costa do Espírito Santo.

Na expedição do "Toko-Marū", realizada em 1957 (Japão, 1963), observouse a existência de temperaturas menores do que $20,0^{\circ} \mathrm{C}$ na superfície, em toda região costeira compreendida entre a Baía de Guanabara e Cabo Frio.

Foram constatadas condições de ressurgência ao sul de Cabo Frio, no perfíl A, figura 4, realizado no período de 10 a 14 de maio de 1960 e apresentada no relatório da viagem do N/Oc. "Almirante Saldanha", (Brasil, 1960).

Emílsson (1961), baseado nos dados de três cruzeiros oceanográficos realizados em 1956, sugeriu que a ressurgência se mantém pelo processo termohalino causado pela radiação solar que, aquecendo a água ressurgente (fria e de baixa salinidade), provoca a diminuição de sua densidade. Ora, para que a estabilidade dinâmica seja mantida, as águas aquecidas são transportadas ao largo, ocasionando movimentos ascendentes de águas de camadas mais profundas que, por sua vez, sofrem diminuição de densidade. Este processo deve ocorrer com continuidade, para ocasionar anomalia na distribuição das propriedades 
citadas. Tal mecanismo deve ser, a par com ventos dominantes, o fator predominante de uma ressurgência permanente e periódica nas vizinhanças de outras zonas tropicais e sub-tropicais dos oceanos, onde a salinidade diminui com a profundidade.

Em 1966, o N/Oc. "Almirante Saldanha" manteve-se fundeado durante nove dias, ao norte de Cabo Frio, latitude de $22^{\circ} 55^{\prime} 05^{\prime \prime} \mathrm{s}$ e longitude de $40^{\circ} 52^{\prime} 02^{\prime \prime} \mathrm{W}$, realizando setenta e cinco estações, com intervalos de três horas, entre uma estação e outra. Silva \& Rodrigues (1966), a partir destas observações, descreveram as modificações da estrutura vertical das massas de àgua sob a ação do vento.

Mascarenhas et al. (1971a), analisando os resultados do período de janeiro de 1968 a julho de 1969, observaram maior intensidade na ressurgência a oeste de Cabo Frio, que provocou anomalias na distribuição da temperatura na superfície, com um mínimo de $\mathrm{T} \cong 15,0^{\circ} \mathrm{C}$.

Matsuura (1971), estudando a distribuição e a abundância de larvas de sardinha na região da Ilha Grande, Rio de Janeiro, realizou cinco cruzeiros oceanográficos no período de 1969-70, quando observou temperaturas mínimas, para a superfície de $10 \mathrm{~m}$, na latitude de $23^{\circ} 10^{\prime} \mathrm{s}$ e longitude de $43^{\circ} 05^{\prime} \mathrm{W}$, novembro de $1969, \mathrm{~T} \cong 16,0^{\circ} \mathrm{C}$, figura $14 \mathrm{c}$, e, janeiro de 1970 , na latitude de $23^{\circ} 00^{\prime} \mathrm{S}$ e longitude de $42^{\circ} 30^{\prime} \mathrm{W}, \mathrm{T} \cong 15,0^{\circ} \mathrm{C}$, figura $14 \mathrm{~d}$.

Mascarenhas et al. (1971b) evidenciaram a ressurgência entre a Ilha dos Franceses e Itha de Cabo Frio, figura 20, atravēs do filme do Imageador Infra-Vermelho obtido em julho de 1969 com o imageador de 2 canais RS-14, instalado a bordo de uma aeronave da National Aeronautics and Space Administration (NASA).

\section{MÉTODOS E INSTRUMENTOS}

Os dados analógicos de temperatura e de salinidade na superfície do mar na região de Cabo Frio, foram obtidos com um termosalinógrafo marca BissetBerman, mod. $6.600 \mathrm{~T}$, cuja instalação e funcionamento a bordo do N/0c. "Prof. W. Besnard" foram descritos por Ikeda (1971). 
Nesse equipamento, a temperatura é medida através de um par de termistores, instalados na tubulação de admissão de água para refrigeração do motor do navio, situada a uma distância de três metros abaixo da linha de ägua.

Para a medição da salinidade, foi instalada uma derivação no mesmo sistema de refrigeração. Esta derivação faz a amostra de água circular através de uma coluna eliminadora de bolhas de ar e de um reservatório que contém um sensor de salinidade (célula indutiva), um termômetro de platina de precisão e dois pares de termistores. Estes sensores de temperatura, fazem parte dos módulos de compensação de temperatura.

Os sinais são calibrados de tal forma a registrarem simultaneamente a temperatura e a salinidade com a precisão de $\pm 0,1^{\circ} \mathrm{C}$ e $\pm 0,03^{\circ} \%$, respectivamente. Os dados de temperatura podem ser registrados em cinco escalas diferentes, com amplitudes de $10,0^{\circ} \mathrm{C}$ cada uma, cobrindo um intervalo de $-2,0$ à $36,0^{\circ} \mathrm{C}$ e $2,0^{\circ} \%$ cada uma, cobrindo um intervalo de 28,0 à $37,5 \%$. Há ainda duas escalas adicionais de 20,0 à $30,0^{\circ} \%$ e e 28,0 à $38,0^{\circ} \%$.

As informações contínuas e rápidas do termosalinógrafo possibilitam o conhecimento "quase-sinótico" da distribuição das propriedades oceanogrāficas, o que conseqüentemente permite seu melhor correlacionamento com os ventos e outros processos de interação ar-mar para o fenômeno que se desenvolve dentro da escala média (duração de alguns dias, compreendendo escala espacia1 de 10 até $100 \mathrm{~km}$ ).

Os desvios observados nas medições contínuas de temperatura e de salinidade, obtidos pela comparação com medições diretas dessas propriedades, estão dentro da precisão indicada pelo fabricante, $\pm 0,1^{\circ} \mathrm{C}$ e $\pm 0,03^{\circ} /$ oo para a temperatura e a salinidade, respectivamente (Fig. 2).

Utilizando-se o computador IBM/360, do Setor de Matemātica Aplicada (SEMA) do Instituto de Física da Universidade de São Paulo, calculou-se os valores de $\sigma_{T}$ para os dados do termosalinógrafo e das estações oceanográficas, através do programa DENOX II, desenvolvido pelo Departamento de Oceanografia Física do Instituto Oceanogräfico da Universidade de São Paulo, para anālise de distribuição de densidade. 0 parâmetro $\sigma_{\mathrm{T}}=\left(\rho_{\mathrm{S}, \mathrm{T}, 0}-1\right) \cdot 10^{3}$ associado à densidade, é calculado nesse programa por meio das equações empíricas indicadas por Lafond (1951). 


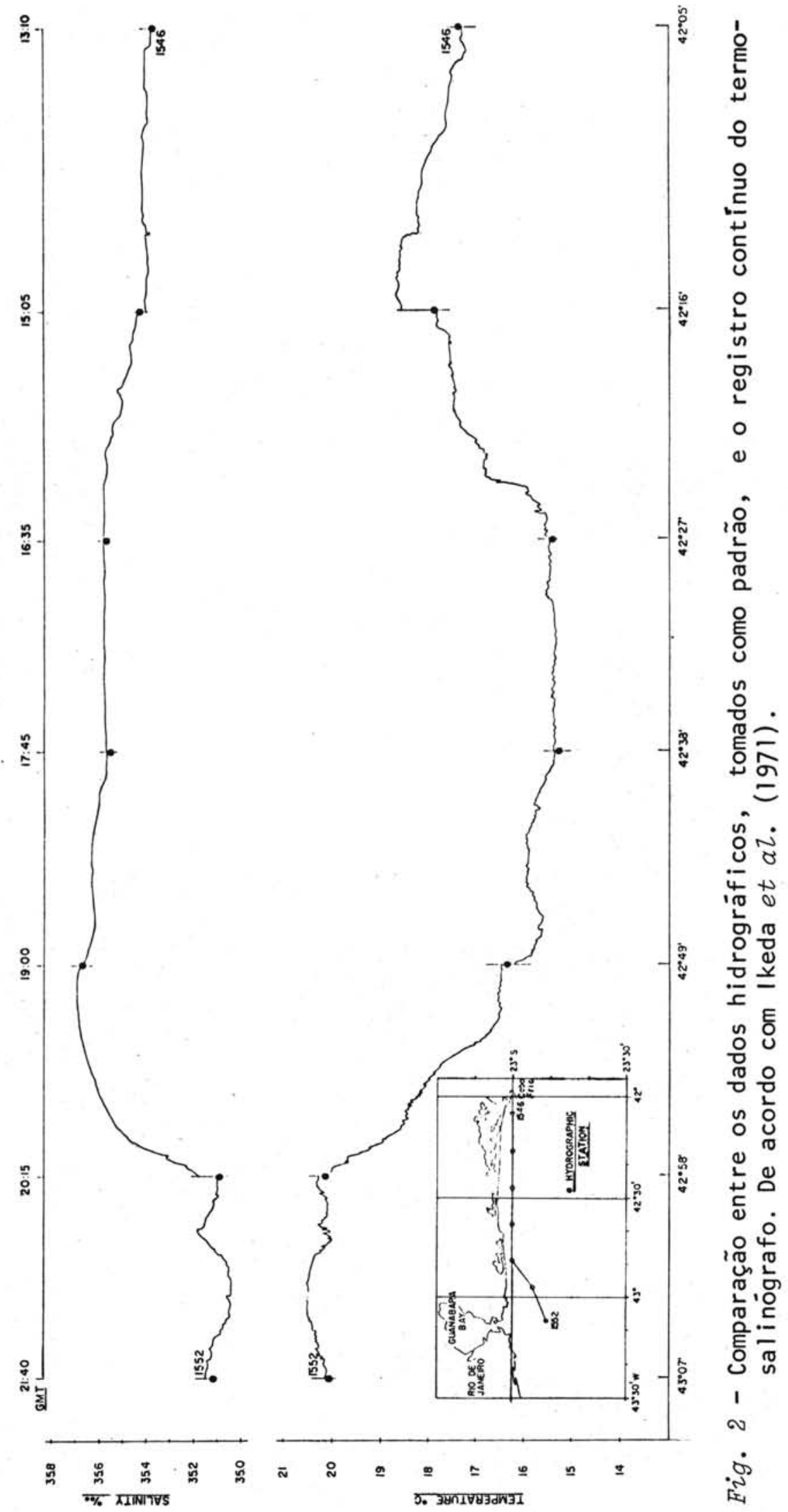


0 planejamento da viagem do projeto "Sensores Remotos" foi realizado em conjunto pelo Instituto de Pesquisas Espaciais (INPE), pela Diretoria de Hidrografia e Navegação (DHN), pelo Instituto de Pesquisas da Marinha (IPQm) e pelo Instituto Oceanogräfico da USP (IOUSP), tendo sido a primeira etapa realizada pelo INPE/IOUSP, e a segunda pela DHN, IPQm e INPE.

A coleta de dados foi iniciada no dia 17 de agosto e terminada no dia 26 de agosto de 1971. Durante esse período puderam ser realizadas sete passagens na mesma ārea, obtendo-se assim, num período de nove dias, várias distribuições dos parâmetros oceanogräficos de superfície. Entre os dias 21 e 24, foram realizadas duas redes de estações oceanogrä́ficas (Fig. 1), num total de quarenta estações, com medições de temperatura e salinidade, desde a superfície até às proximidades do fundo.

Para os dados das estações oceanogräficas com respeito às temperaturas lidas nos termômetros de reversão, protegidos e instalados nas garrafas-deNansen, foram feitas correções devidas à dilatação volumétrica do sistema termométrico e ao erro índice. A determinação da salinidade das amostras de água do mar coletadas com as garrafas-de-Nansen, foi feita de acordo com as equações recomendadas pelo Joint Panel on Oceanographic Tables and Standards (1966), sendo a "razão de condutibilidade elétrica" ( $\left.R_{t}\right)$ determinada com um salinômetro indutivo marca Beckman, mod. RS-7B, calibrado com "água normal".

Durante as estações, foram observados parâmetros meteorológicos de superfície, tais como: nuvens, temperaturas do ar, umidade relativa, direção e vełocidade do vento e condições do mar. Além das observações de vento, obtidas com um anemômetro durante as estações oceanogräficas, (Figs 3-4) pôdese contar com os dados horārios (velocidade média e direção) do vento, observado na estação meteorológica da Companhia Nacional de Alcalis, 1ocalizada na latitude de $22^{\circ} 53^{\prime} \mathrm{S}$ e longitude de $42^{\circ} 02^{\prime} \mathrm{W}$, Cabo Frio (Figs 5-6).

A posição do navio foi determinada em intervalos de meia hora, através da fixação dos contornos da linha da costa no radar, e, fora do alcance deste, foi obtida por navegação astronômica.

Na classificação das massas de āgua, muitas vezes nos utilizamos da indicada por Emílsson (1961) que, utilizando como critério para essa classificação a salinidade, identificou a presença das seguintes massas de água na 


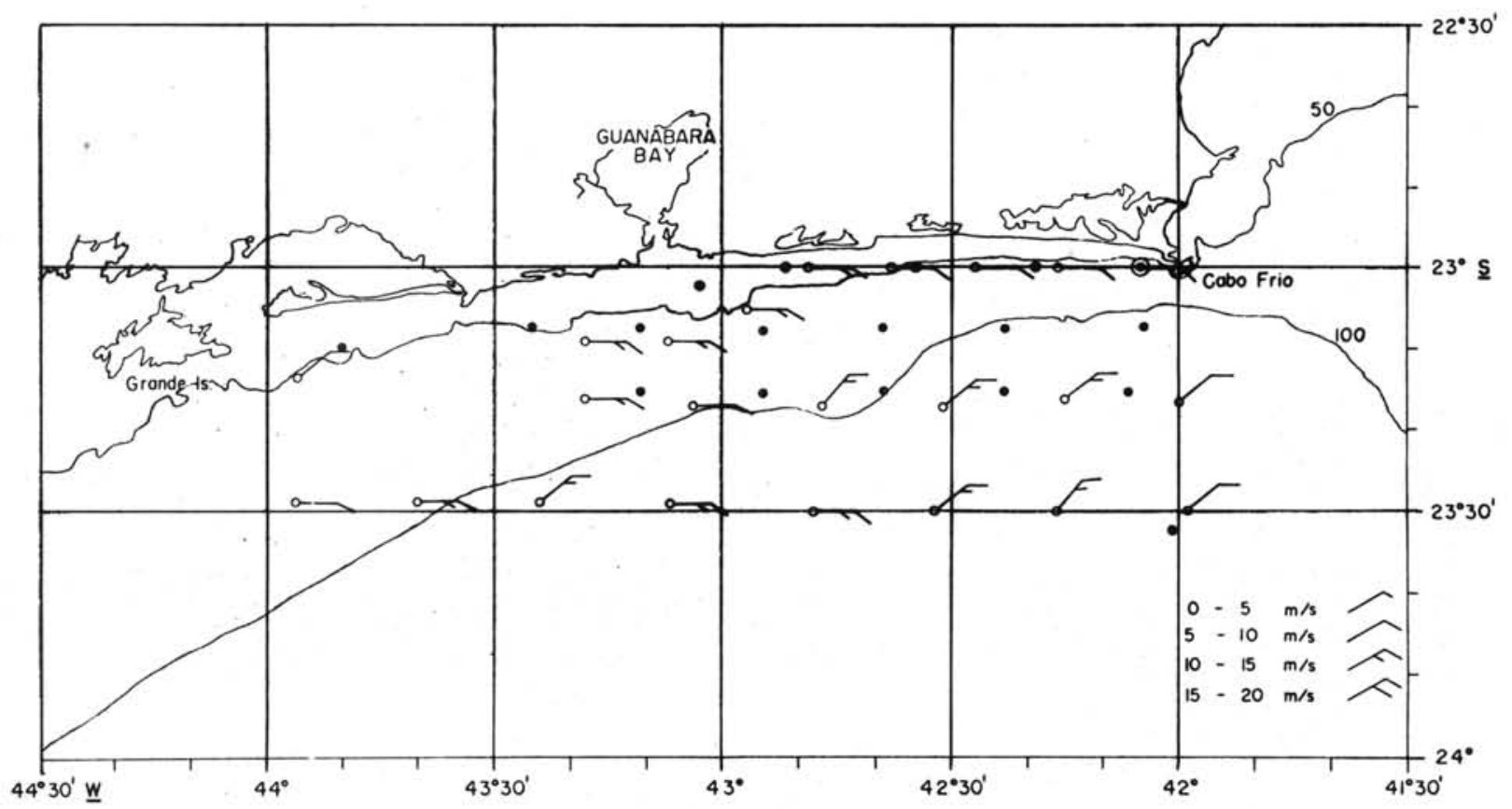

Fig. 3 - Direção e velocidade dos ventos observados durante as estações hi drogräficas no período de $21 / 08 / 71$ a 23/08/71. De acordo com lkeda et al. (1971).

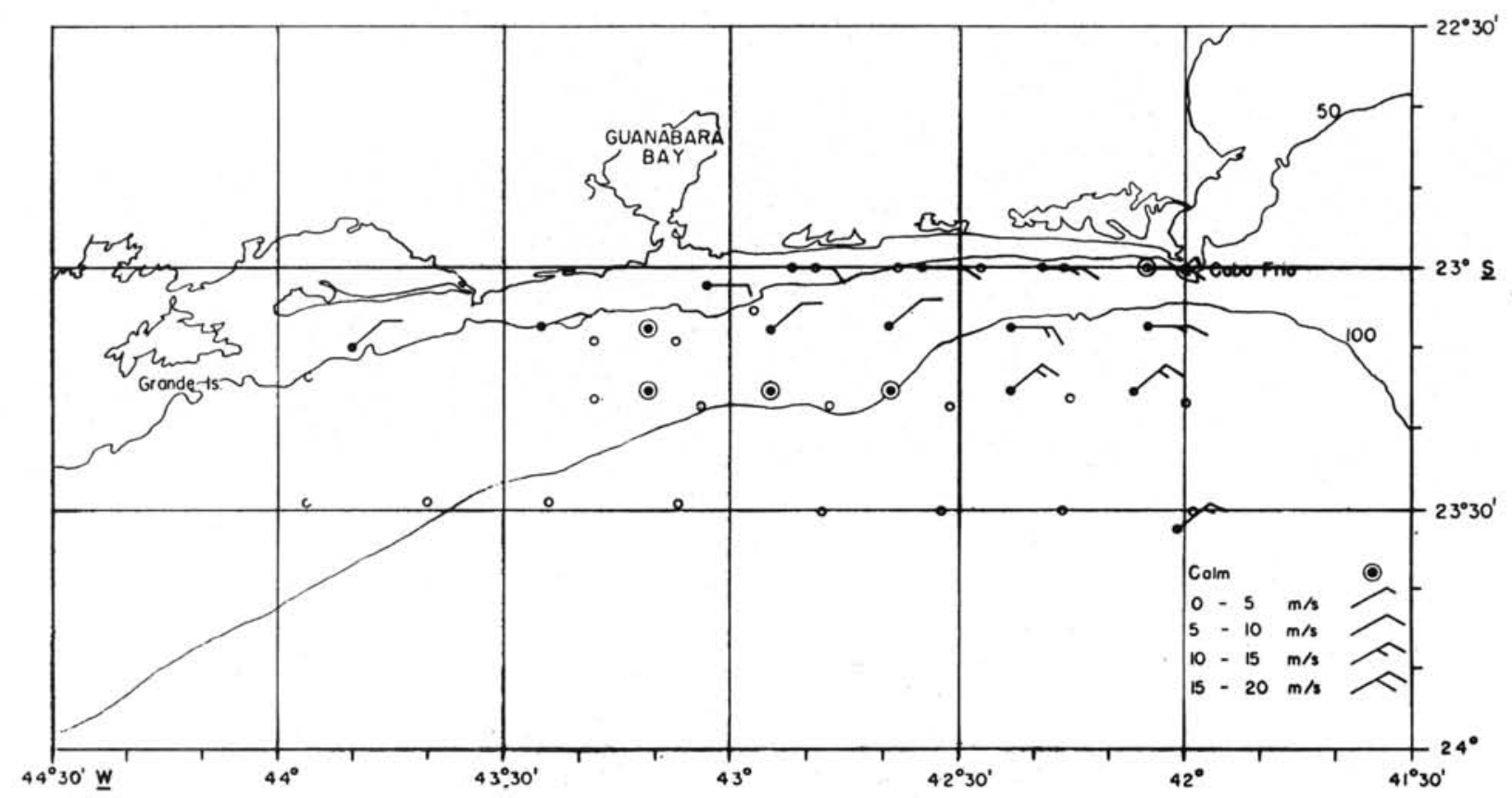

Fig. 4 - Direção e velocidade dos ventos observados durante as estações hidrogrä́ficas no período de $23 / 08 / 71$ a 24/08/71. De acordo com Ikeda et al. (1971). 
região em estudo:

Agua Costeira $\quad(\mathrm{S}<35,0 \%)$

Āgua de Plataforma $(35,0<\mathrm{S}<36,0 \%)$

Āgua Tropical (S $>36,0 \%$ oo

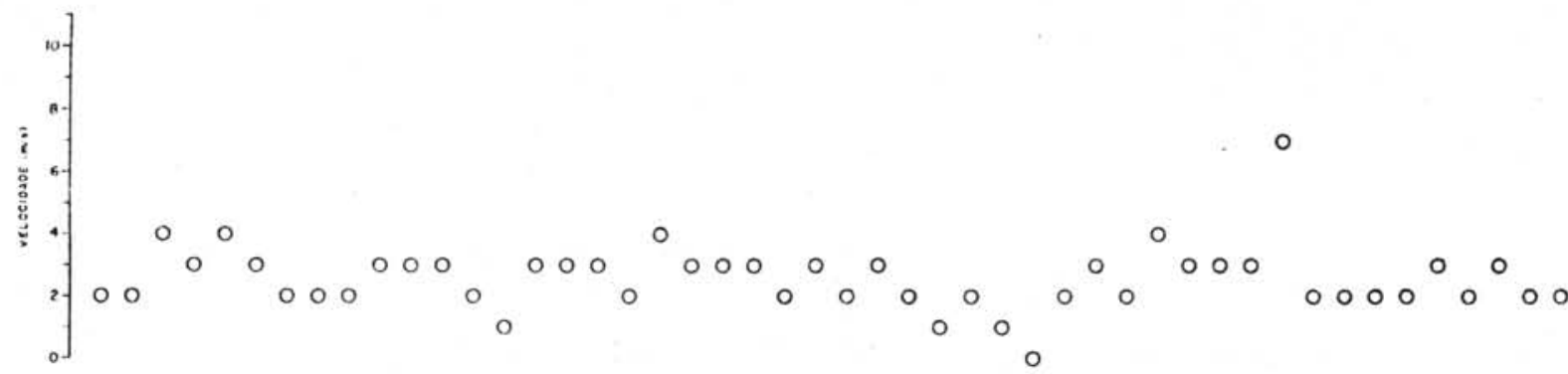

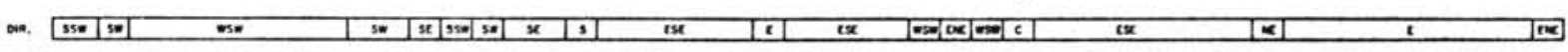
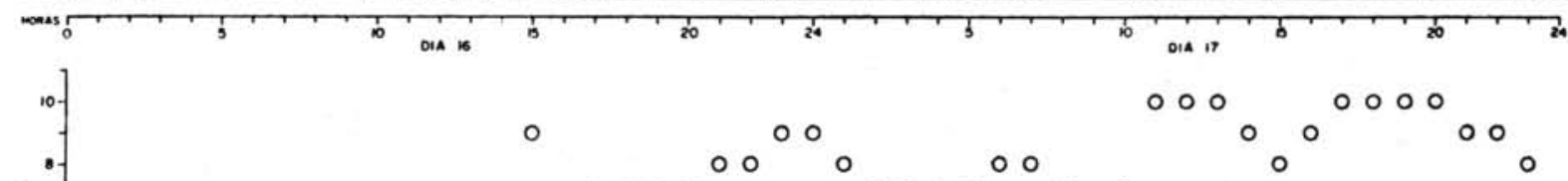

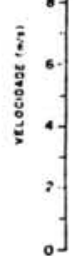
$0000 \quad 000000$ $000^{00} 0$ $0^{\circ} 0^{0} 0^{\circ}$

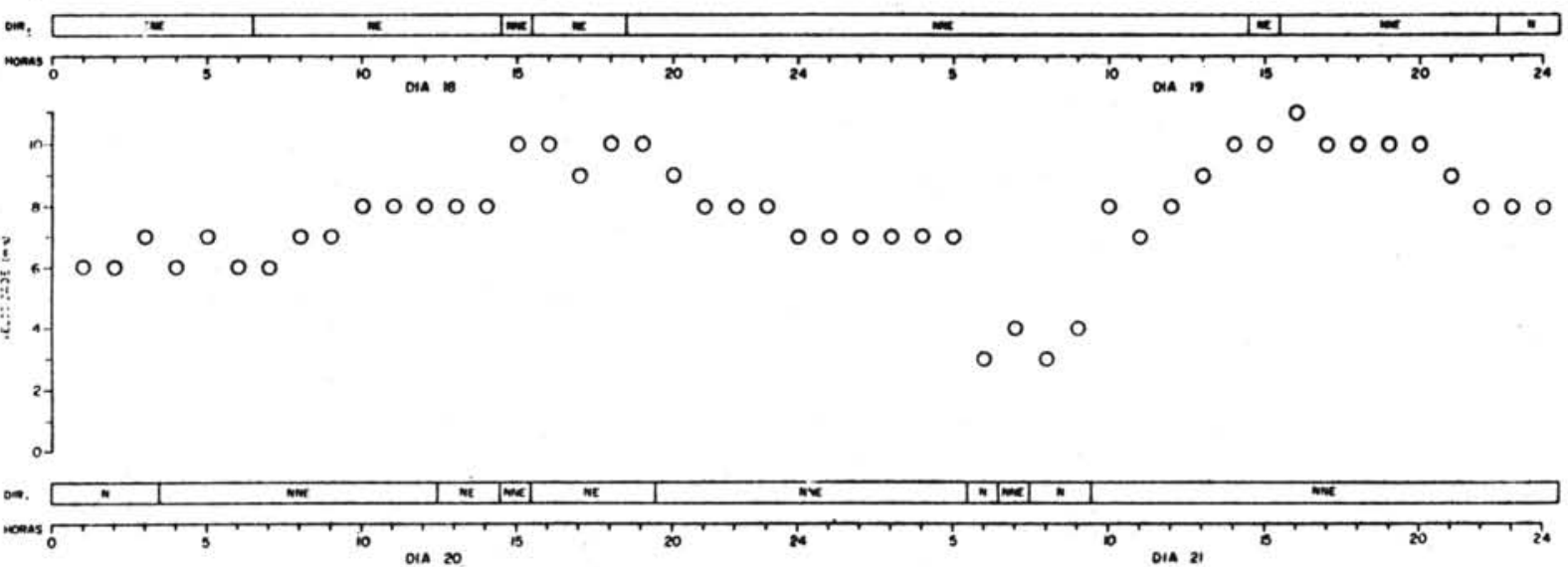

Fig. 5 - Variação horäria do vento (direção e velocidade) para o período de $16 / 08 / 71$ a $21 / 08 / 71$, observada na estação meteorolögica da Companhia Nacional de Álcalis, Cabo Frio. 

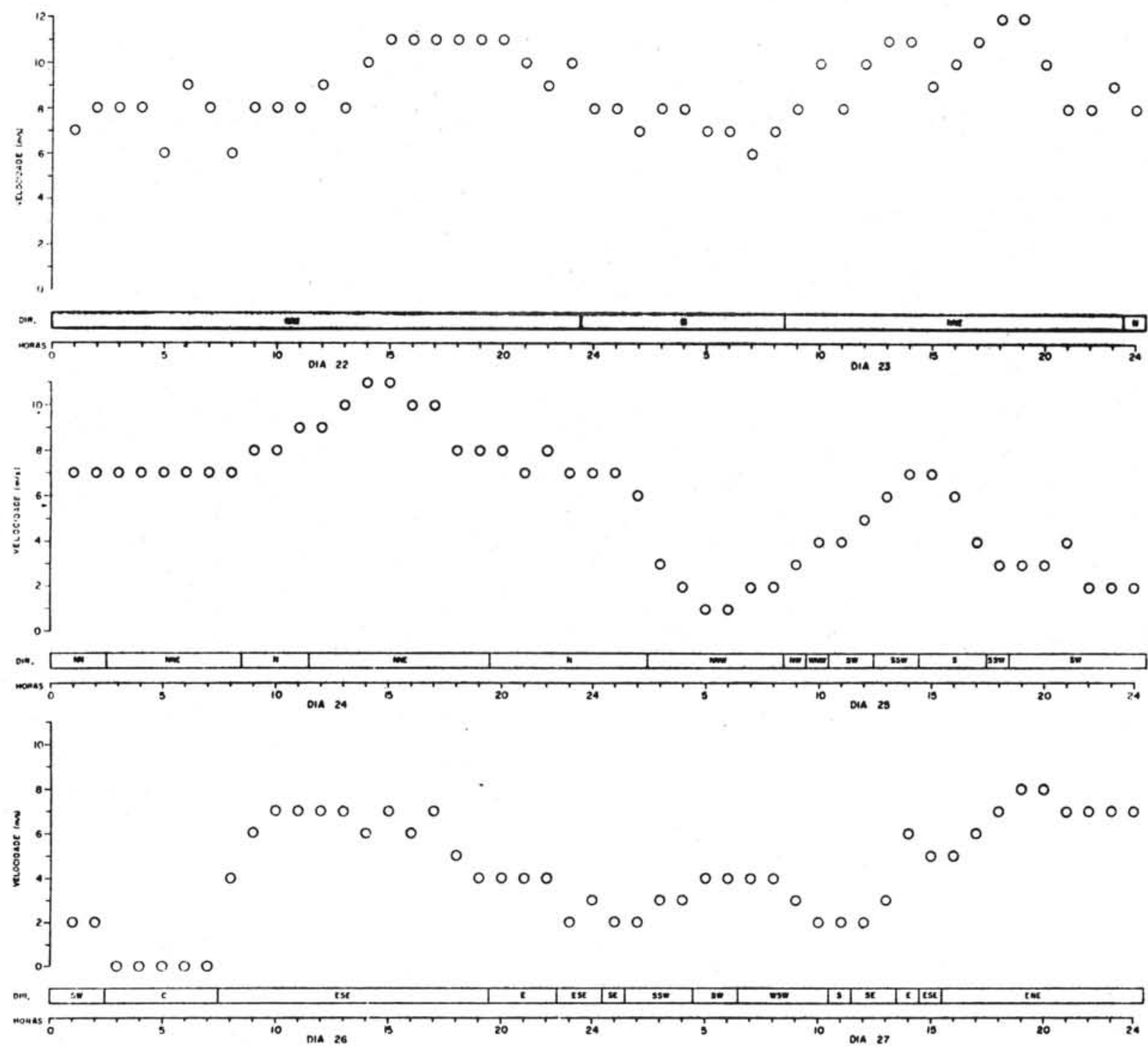

Fig. 6 - Variação horäria do vento (direção e velocidade) para o período de $22 / 08 / 71$ a $27 / 08 / 71$, observada na estação meteorolögica da Companhia Nacional de Âlcalis, Cabo Frio.

PROCESSOS RESPONSĀVEIS PELA VARIAÇÃO DA TEMPERATURA E DA SALINIDADE NA SUPERFİCIE DO MAR

Como a preocupação principal, neste trabalho, è descrever as variações da temperatura e da salinidade numa escala temporal de dias, far-se-á, algumas considerações teóricas sobre a distribuição das propriedades da āgua do mar. 
Para que as técnicas do cálculo diferencial e integral possam ser utilizadas, assume-se que essas propriedades sejam expressas por funções contínuas das variáveis independentes e que todas as demais condições de regularidade sejam tambēm satisfeitas.

Para mostrar que as hipóteses acima constituem uma primeira aproximação do que realmente ocorre no oceano, a Figura 2 evidencia a complexidade das distribuições de temperatura e de salinidade na superfície do mar.

EQUAÇÃO DE CONSERVAÇÃO

A água do mar está em constante movimento em virtude da ação simultânea dos processos de interação ar-mar e gravitacionais. Seja $B(\vec{r}, t)$ o campo tensorial representativo de qualquer propriedade física extensiva desse fluido. Seja um domínio V, limitado por uma superfície fechada S, que se move com uma velocidade $\vec{V}$ relativamente a um referencial.

Supondo que $B(\vec{r}, t)$ seja contínua em $V$, pode-se escrever a equação integral abaixo, representativa da lei da conservação dessa propriedade nesse elemento de volume que se move com o fluido:

$$
\frac{d B(\vec{r}, t)}{d t}=\int_{V}^{q}(\vec{r}, t) d V+\int_{S} \vec{F} \cdot \vec{n} d S[B] \cdot T^{-1}
$$

onde: $q(\vec{r}, t)$ é uma função dada, que representa a taxa de geração ou consumo da propriedade por unidade de volume e $\vec{F}$ representa o fluxo difusivo através de $\mathrm{S}$ e que é gerado por forças ou pressões internas e pelos gradientes da propriedade.

Se B é uma propriedade que não admite fontes ou sumidouros $(q=0)$ e, alēm do mais, é não difusiva $(\overrightarrow{\mathrm{F}}=0)$, segue-se que:

$$
\frac{d B(\vec{r}, t)}{d t}=0 \rightarrow B(\vec{r}, t)=c t e .
$$


o que significa que a propriedade se mantém constante à medida que o elemento de volume $\mathrm{V}$ se move com o fluido.

Seja m a massa do fluido contido em $\mathrm{V}$ e $\rho=\delta \mathrm{m} / \delta \mathrm{V}$ a sua densidade. A propriedade intensiva $b(\vec{r}, t)$ associada a $B(\vec{r}, t)$ é também por definição:

$$
b(\vec{r}, t)=\frac{B(\vec{r}, t)}{m}[b]=[B] M^{-1}
$$

e a concentração $C(\vec{r}, t)$ da propriedade $B$ em $V$ é dada por:

$$
C(\vec{r}, t)=\rho b(\vec{r}, t)[C]=[B] \cdot L^{-3}
$$

Portanto, a quantidade da propriedade $B(\vec{r}, t)$ no volume $V$ se calcula mediante a seguinte integral:

$$
B(\vec{r}, t)=\int_{V} \rho b(\vec{r}, t) d V=\int_{V} C(\vec{r}, t) d V \quad[B]
$$

Conseqüentemente, a lei de conservação expressa pela equação 1 , se reduz a:

$$
\frac{d}{d t} \int_{v} C(\vec{r}, t) d V=\int_{v} q(\vec{r}, t) d V+\int_{S} \vec{F} \cdot \vec{n} d S
$$

Assumindo-se vālidas as hipóteses do Teorema do transporte de Reynolds, o primeiro membro da equação 6 , pode ser escrito da seguinte forma:

$$
\frac{d}{d t} \int_{v} C(\vec{r}, t) d V=\int_{v} \frac{d}{d t}[C(\vec{r}, t) d v]
$$

Aplicando a fórmula de expansão de Euler:

$$
\frac{\mathrm{d}(\mathrm{dV})}{\mathrm{dt}}=\nabla \cdot \overrightarrow{\mathrm{v}} \mathrm{dV}
$$


(onde $\nabla$ é o operador de Laplace) na derivação do integrando do segundo membro da equação 7 , vem:

$$
\frac{d}{d t} \int_{v} C(\vec{r}, t) d V=\int_{v}\left(\frac{d C}{d t}+C \nabla \cdot \vec{v}\right) d V
$$

Substituindo-se a equação 9 na equação 6 , vem:

$$
\int_{V}\left(\frac{d C}{d t}+C \nabla \cdot \vec{v}\right) d V=\int_{v} q(\vec{r}, t) d V+\int_{S} \vec{F} \cdot \vec{n} d S
$$

Aplicando-se o Teorema da divergência no último têrmo do segundo membro da equação 10 , vem:

$$
\int_{S} \overrightarrow{\mathrm{F}} \cdot \overrightarrow{\mathrm{n}} \mathrm{dS}=\int_{\mathrm{v}} \nabla \cdot \overrightarrow{\mathrm{F}} \mathrm{dV}
$$

Substituindo, agora, a equação 11 na equação 10, reunindo-se os termos dos dois membros sob um único sinal de integração e levando-se em conta que $\mathrm{V}$ é um volume substantivo qualquer, segue-se a seguinte equação diferencial para a lei de conservação de uma propriedade qualquer de um meio contínuo:

$$
\frac{d C}{d t}+C \nabla \cdot \vec{V}=q(\vec{r}, t)+\nabla \cdot \vec{F}[B] L^{-3} T^{-1}
$$

Levando-se em conta que a variação total (dc/dt), denominada em mecânica dos fluidos de derivada substancial, pode ser expressa por:

$$
\frac{d C}{d t}=\frac{\partial C}{\partial t}+\vec{V} \cdot \nabla C
$$

onde: $\partial c / \partial t$ é a variação local e que pode somente ocorrer por conta das variações do campo da propriedade;

$\vec{V} . \nabla C$ è a variação convectiva, mais comumente denominada em oceanografia de variação advectiva, por representar a variação do campo da propriedade na presença de correntes. 
Combinando as equações 12 e 13, vem:

$$
\frac{\partial C}{\partial t}+\vec{V} \cdot \nabla C+C \nabla \cdot \vec{V}=q+\nabla \cdot \vec{F}
$$

0 último termo do primeiro membro desta equação representa a contribuição da divergência do campo de velocidade para alterar a concentração da propriedade.

Devido à pequena dimensão da região em estudo, abrangendo na direção meridional apenas $1^{\circ}$ de latitude, pode-se desprezar a curvatura do globo terrestre e assumir uma superfície plana para o mar. Neste caso, o campo de uma propriedade qualquer pode ser referida a um sistema de coordenadas cartesianas ortogonais $O x_{i}(i=1,2,3)$ com o plano $O x_{1} x_{2}$ localizado sobre a superfície do mar. Os eixos sendo orientados da seguinte maneira:

$O x_{1}$ tomado paralelamente à costa e orientado positivamente para $\mathrm{E}$ (leste), $O x_{2}$ perpendicular a $O x_{1}$ e orientado positivamente para $N$ (norte) e o eixo $O x_{3}$ com direção e sentido da aceleração da gravidade.

Para tornar a notação componente mais compacta, utiliza-se a convenção de soma de Einstein para tensores cartesianos de segunda ordem. Neste caso, a equação 14 se reduz:

$$
\frac{\partial C}{\partial t}+\frac{\partial\left(C V_{i}\right)}{\partial x_{i}}=q+\frac{\partial F_{j}}{\partial x_{j}}[B] L^{-3} T^{-1}
$$

onde: $V_{i}$ são os componentes da velocidade $\vec{V}$ e $F_{j}$ são os componentes do fluxo difusivo através da superfície $\mathrm{S}$.

Os componentes $F_{j}$ do fluxo difusivo, na hipótese de um fluido isotrópico, são dados pela chamada primeira lei de Fick:

$$
F_{j}=-D \frac{\partial C}{\partial x_{j}}[B] L^{-2} T^{-1}
$$


onde: $\mathrm{D}$ é o coeficiente de difusão molecular, cuja dimensão é $\mathrm{L}^{2} \mathrm{~T}^{-1}$. Esta lei estabelece que o fluxo difusivo é diretamente proporcional ao gradiente da concentração da propriedade. 0 sentido deste fluxo é das regiões de alta concentração para as de baixa.

Levando-se em conta a equação 16 , obtém-se a seguinte expressão para a lei de conservação:

$$
\frac{\partial C}{\partial t}+\frac{\partial\left(C_{i}\right)}{\partial x_{i}}=q-\frac{\partial}{\partial x_{j}}\left(D \frac{\partial C}{\partial x_{j}}\right)
$$

EQUAÇÃO DA CONTINUIDADE

A equação da continuidade que expressa a conservação de massa $(B=m$ e, conseqüentemente, $\mathrm{b}=1$ e $\mathrm{C}=\rho$ ), é um caso particular da equação 17 que se obtém desprezando-se as fontes (sumidouros) e a difusão de massas. Uma forma desta equação é dada por:

$$
\frac{\partial \rho}{\partial t}+\frac{\partial\left(\rho v_{i}\right)}{\partial x_{i}}=0
$$

O REGIME TURBULENTO DOS MOVIMENTOS OCEÂNICOS E COSTEIROS

A água do mar é um fluido de pequena viscosidade e, portanto, é de se esperar a ocorrência dos regimes laminar e turbulento em seus movimentos. Mostra-se, que mesmo desprezando os principais processos geradores de turbulência das águas que se situam na plataforma continental (agitação produzida por ventos e marés), há forte evidência de que tão logo seu movimento se inicie, o regime laminar, para o qual a equação de conservação foi deduzida, sofre transição para o regime turbulento. 
As condições de transição do regime laminar para o turbulento (ou viceversa) foram estudadas, detalhadamente com resultados experimentais em 1aboratório, por Reynolds em 1883. Nesses estudos ficou demonstrado que essa transição, identificada pela presença de um rápido processo de mistura (causada pelo aparecimento de movimentos turbilhonares), pode ser prevista pelo conhecimento dos valores críticos $\left(R_{C}\right)$ de um número adimensional, denominado de número de Reynolds. Para um escoamento com velocidade $V(V=|\vec{V}|)$, num tubo de diâmetro d, esse número é definido pela seguinte equação:

$$
R=\frac{\rho V d}{\mu}
$$

onde: $\mu$ é o coeficiente de viscosidade. Este coeficiente tem uma pequena dependência com a salinidade e, para a água pura, ela varia no intervalo de $10^{-1} \mathrm{gcm}^{-1} \mathrm{~s}^{-1}$ à $0,81 \cdot 10^{-3} \mathrm{gcm}^{-1} \mathrm{~s}^{-1}$ quando a temperatura varia de 20,0 à $30,0^{\circ} \mathrm{C}$, respectivamente.

Da equação acima, seguem as seguintes definições para os números críticos de Reynolds (número crítico superior, $R_{c s}$ e o número crítico inferior, $\mathrm{R}_{\mathrm{ci}}$ ):

$$
\mathrm{R}_{\mathrm{cs}}=\frac{\rho \mathrm{v}_{\mathrm{s}} \mathrm{d}}{\mu} \quad \mathrm{R}_{\mathrm{ci}}=\frac{\rho \mathrm{v}_{\mathrm{i}} \mathrm{d}}{\mu}
$$

onde: $V_{S}$ e $V_{i}$ são as chamadas velocidades críticas superior e inferior, respectivamente.

$\bar{A}$ partir do conhecimento experimental dos números $R_{c s}$ e $R_{c i}$, Reynolds demonstrou ser possível a previsão do regime do movimento de um determinado escoamento, mediante os seguintes critérios:

Se $\mathrm{R}<\mathrm{R}_{\mathrm{ci}}$ - o movimento é laminar

Se $R>R_{c s}$ - o movimento é turbulento

onde: $\mathrm{R}$ è o número de Reynolds para a condição do escoamento, determinado pela equação 19 . 
Embora o número $R_{c s}$ ( $R_{c i}$ ) dependa de värias condições, tais como, o estado inicial do fluido e a rugosidade do tubo, ele é de grande importância nas aplicações práticas, pois define a condição à partir da qual o regime laminar passa a turbulento.

No estudo do regime do movimento em canais com superfície livre, o chamado perímetro hidrāulico $\left(\mathrm{P}_{\mathrm{h}}\right)$ è usado como parâmetro de comprimento na definição de número de Reynolds, que passa a ser definido por:

$$
\mathrm{R}=\frac{\rho \mathrm{V} \cdot \mathrm{P}_{\mathrm{h}}}{\mu}
$$

onde: $\mathrm{P}_{\mathrm{h}}$ é igual a razão entre a ārea da secção transversal (A) do canal pelo perímetro molhado $\left(\mathrm{P}_{\mathrm{m}}\right)$.

Nesse movimento, os números críticos $R_{c i}$ e $R_{c s}$ são praticamente iguais e como não há necessidade de distinção, fazendo-se referência simplesmente ao número crítico de Reynolds $\left(R_{C}\right)$. $R_{C}$, alēm de depender das condições $j a ̄$ mencionadas para o movimento em tubos, também depende da forma da secção transversal do canal e seus valores típicos são, em geral, menores do que $4.10^{3}$ (Owen, 1954; Straub, Silberman \& Ne1son, 1957).

Idealizando agora o movimento ao longo da costa como um escoamento num canal de secção transversal triangular, com uma inclinação da plataforma continental em relação à horizontal menor do que $1^{\circ}$, segue-se que o perímetro hidráulico é aproximadamente igual a $0,5 \mathrm{~h}$ (onde $\mathrm{h}$ é a profundidade máxima da secção). Adotando os seguintes valores:

$$
\begin{aligned}
& \mathrm{V}=1 \mathrm{~mm} / \mathrm{s}=10^{-1} \mathrm{~cm} / \mathrm{s} \\
& \mu=10^{-2} \mathrm{gcm}^{-1} \mathrm{~s}^{-1} \\
& \mathrm{~h}=100 \mathrm{~m}=10^{4} \mathrm{~cm}
\end{aligned}
$$

obtem-se o número de Reynolds igual a $5.10^{4}$.

Em virtude da inexistência de medições experimentais do número $R_{c}$ para o movimento acima idealizado, toma-se como referência o valor máximo obtido 
experimentalmente para canais amplos e com superfície livre $\left(R_{c}=4.10^{3}\right)$. Conseqüentemente, $R>R_{c}$ o movimento é turbulento mesmo para pequenas velocidades $(\mathrm{V}=0,1 \mathrm{~cm} / \mathrm{s})$.

Quando da análise dos resultados experimentais, por exemplo Figuras 2728, observa-se que a água da região em estudo não é homogênea, isto é, seu campo de massa apresenta-se estratificado.

Reynolds, em suas experiências de laboratōrio, não se preocupou com fluidos não homogêneos em virtude da pequena escala dos movimentos estudados.

Nos movimentos de grandes volumes de água, tal como no oceano ou mesmo em canais amplos, em que o fluido è não homogêneo, a influência da estratificação de massa do fluido deve ser levada em conta na discussão de seus movimentos e na distribuição das propriedades. Com efeito, se a energia cinética da componente vertical do movimento turbulento não é suficiente para superar os efeitos da força da gravidade e do empuxo, então o movimento vertical turbulento è suprimido.

A influência da estratificação de massa sobre os movimentos turbulentos horizontais é muito menor. Neste caso, os componentes horizontais de movimento turbulento precisam superar os efeitos associados e menores da força de inércia e dos gradientes horizontais de pressão.

Prandt, em 1930, mostrou que a estabilidade vertical de um fluido em movimento depende do parâmetro adimensional $\left(R_{i}\right)$, denominado de número de Richardson:

$$
R_{i}=\frac{\frac{g}{\rho}\left(\frac{\partial \rho}{\partial x_{3}}\right)}{\left(\frac{\partial v_{3}}{\partial x_{3}}\right)^{2}}
$$

onde: $g$ è a aceleração da gravidade; $\rho$ é a densidade e $v_{3} \bar{e}$ o componente vertical da velocidade. 
0 numerador da equação 22 é proporcional à potência por unidade de volume que o movimento turbulento deve realizar contra a força de gravidade. 0 denominador, por sua vez, é proporcional à taxa por unidade de volume segundo à qual a energia cinética do movimento se transfere para o movimento turbulento. Pode-se, portanto, relacionar os seguintes critérios gerais para a ocorrência de estabilidade (turbulência) vertical:

Se $R_{i}>1$ - o movimento é verticalmente estável e, portanto, laminar;

Se $R_{i}<1$ - o movimento é verticalmente instáve1 e, portanto, turbulento.

De acordo com Schlichting (1968, p. 492), menciona-se os seguintes resultados que tiveram como objetivo estabelecer um critério teórico e experimental mais rígido do que o exposto acima: Taylor em 1931 e Goldstein em 1939, foram os primeiros a aplicarem o método das pequenas perturbações para a resolução desse problema. Assumindo gradientes verticais constantes da densidade e da componente vertical da velocidade num fluido infinito determinou-se como limite do número de Richardson, separando os regimes laminar e turbulento, o valor de 1/4. Schlichting em 1935, retomando o problema como um fenômeno de camada limite, verificou que o número crítico de Reynolds $\left(R_{c}\right)$ aumenta rapidamente com o aumento do número de Richardson $\left(R_{i}\right)$, variando de $R_{c}=575$ (quando $R_{i}=0$ e que corresponde a um fluido homogêneo) a $\mathrm{R}_{\mathrm{C}}=\infty$ (quando $\mathrm{R}_{\mathrm{i}}=1 / 24$ ).

Uma comparação entre a teoria e os resultados experimentais mencionados acima, foi feita por Prandt \& Reichardt em 1935. As medições foram realizadas num canal retangular especial, sob condições controladas. Na correlação entre $R_{c}$ e $R_{i}$ apresentada na Figura 7, verifica-se que todos os fluxos laminares caem dentro da região estáve1, enquanto que os fluxos turbulentos caem na região instável. A concordância dos resultados experimentais e teóricos é excelente no que se refere ao limite $R_{i}=1 / 24$, determinado teoricamente por Schlichting (1968).

Os resultados acima, vālidos em escala de laboratōrio e sob condições controladas, quando usados como critérios para previsão do regime de movimento das águas do mar, em geral, não dão resultados concordantes. Assim, por exemplo, não obstante as dificuldades da determinação do número de $\mathrm{R}_{\mathbf{i}}$ 


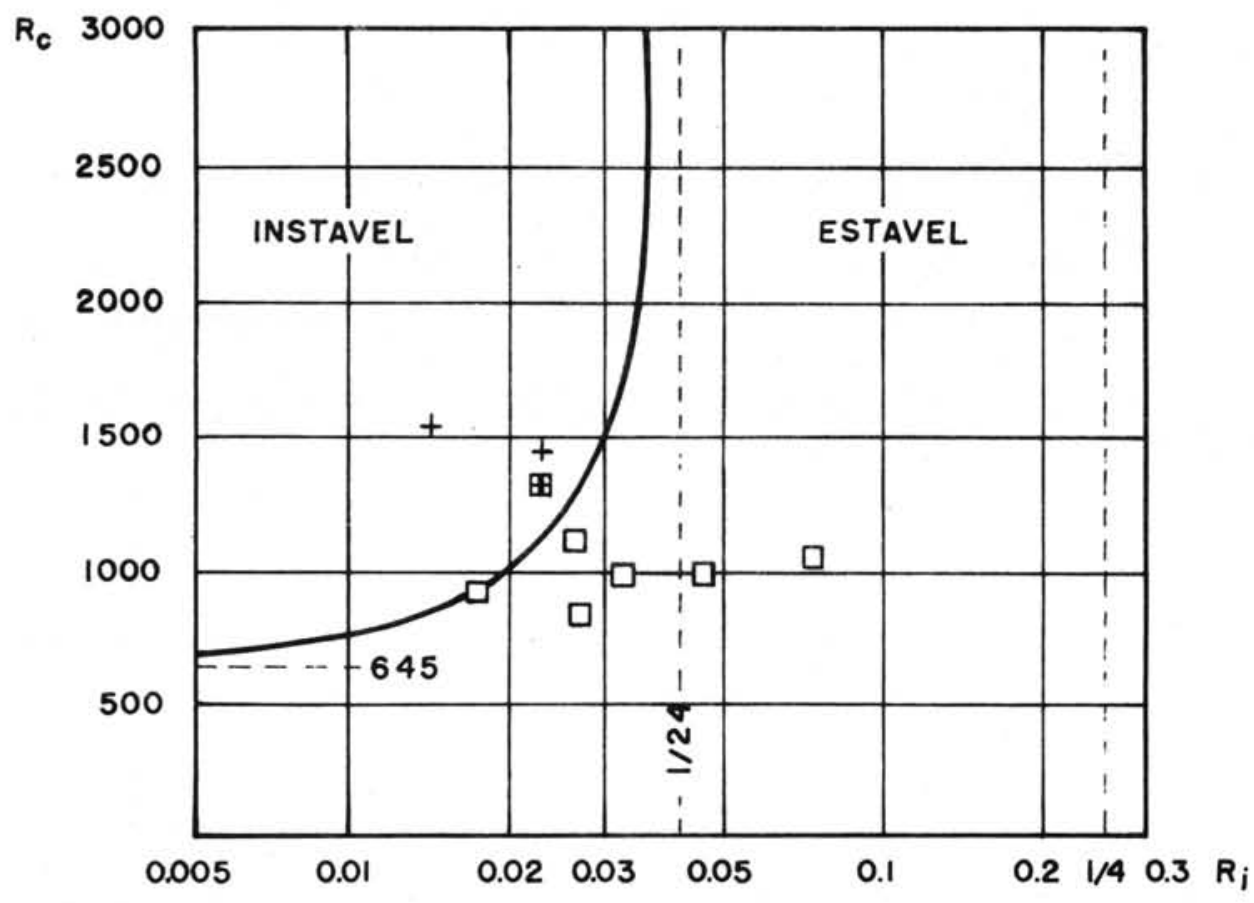

Fig. 7 - Correlação entre o nümero de Reynolds $\left(R_{C}\right)$ e o nümero de Richardson $\left(R_{i}\right)$, determinados experimentalmente. De acordo com Schlichting (1968). (+ turbulento; 口 laminar)

para um movimento de águas costeiras, valores muito maiores do que 1 foram obtidos em movimentos turbulentos. Essa discrepância é compreensível, considerando-se que os seguintes processos enumerados por Bowden (1962), são geradores de turbulência:

a - processos geradores de turbulência vertical:

1 - A ação da tensão de cisalhamento do vento sobre a superfície do mar;

2 - 0 efeito do atrito de fundo sobre as correntes, particularmente, sobre as correntes de maré;

3 - A presença de tensões de cisalhamento nas correntes devido aos gradientes horizontais de pressão. 
b - processos geradores de turbulência horizontal:

1 - Variação horizontal da tensão de cisalhamento do vento sobre a superfície;

2 - Tensões laterais de cisalhamento nos limites costeiros;

3 - Tensões de cisalhamento horizontal nas correntes ou entre correntes adjacentes.

Uma vez gerado um movimento turbulento pela ação dos processos enumerados acima, sua energia cinética tende a se dissipar sob a forma de calor, em virtude dos efeitos viscosos da água do mar. Tomando por base as ordens de grandeza da taxa de dissipação da energia em águas costeiras $\left(10^{-1} \mathrm{erg} \cdot \mathrm{g}^{-1} \mathrm{~s}^{-1}\right)$ e em águas oceânicas de superfície $\left(10^{-2} \mathrm{erg} \cdot \mathrm{g} \cdot \mathrm{s}^{-1}\right)$, Nan'niti (1964) mostrou que os fenômenos em águas razas variam muito mais rapidamente do que em águas profundas. Segue-se, portanto, a maior complexidade dos fenômenos oceanográficos costeiros.

Da termodinâmica sabemos que é necessário converter $4,186.10^{7}$ ergs de energia mecânica em calor, para que a temperatura de uma grama de água se eleve a $1,0^{\circ} \mathrm{C}$. Desprezando-se a pequena diferença entre os valores do calor específico da água e da água do mar, pode-se estimar em $5.10^{3}$ dias o tempo necessário para que a energia dissipada em águas costeiras produza, numa grama de água, diferença de temperatura de $1,0^{\circ} \mathrm{C}$. Este cálculo aproximado mostra que a variação local da temperatura das águas costeiras é regulada essencialmente pelos processos de interação ar-mar, advectivos e difusivos e que a dissipação de energia cinética em calor pode ser desprezada.

EQUAÇÃO DE CONSERVAÇÃO PARA O MOVIMENTO TURBULENTO

Sabe-se que, o ponto de partida para a formulação matemática de qualquer problema que envolve um movimento turbulento, é a equação de conservação: 


$$
\frac{\partial \bar{c}}{\partial t}+\frac{\partial \overline{c v}_{i}}{\partial x_{i}}=-\frac{\partial}{\partial x_{j}}\left(\overline{c^{\prime} v_{i}^{\prime}}+D \frac{\partial \bar{c}}{\partial x_{j}}\right)+q
$$

Na equação acima, $\bar{c}, \bar{v}_{i}, c^{\prime}$ e $v_{i}^{\prime}$ são definidos nas seguintes expressões:

$$
\begin{aligned}
c & =\bar{c}+c^{\prime} \\
v_{i} & =\bar{v}_{i}+v_{i}^{\prime} \quad(i=1,2,3)
\end{aligned}
$$

onde: $\overline{\mathrm{C}}$ e $\overline{\mathrm{V}}_{\boldsymbol{i}}$ são os valores médios (tomados num intervalo de tempo conveniente) da concentração da propriedade e da velocidade, e c', v's são flutuações (de valor médio nulo) que se superpõem à $\bar{C}$ e a $\bar{v}_{i}$ para gerar os valores instantâneos de $\mathrm{C}$ e $\mathrm{V}_{\boldsymbol{i}}$.

A equação 23, se obtém a partir da média (num intervalo de tempo conveniente) da equação que se obtēm a partir da 17, pela substituição dos valores instantâneos de $\mathrm{C}$ e $\mathrm{V}_{i}$ dados pelas expressões 24.

0 termo $\overline{c^{\prime} v_{i}^{\prime}}$ que aparece no segundo membro da equação 23 pode ser relacionado, de acordo com os resultados semi-empíricos da teoria da difusão turbulenta (Okubo, 1970), com o gradiente do valor médio da concentração da propriedade mediante a seguinte equação:

$$
\overline{c^{\prime} v_{i}^{\prime}}=-A_{i} j \frac{\partial \bar{C}}{\partial x_{j}}
$$

onde: $A_{i j}(i, j=1,2,3)$, são os chamados coeficientes de difusão turbulenta.

Como os coeficientes $A_{i j}$ são em geral muito maiores do que $D$, a equação 23 se reduz a:

$$
\frac{\partial \bar{C}}{\partial t}+\frac{\partial \overline{C V}_{i}}{\partial x_{i}}=\frac{\partial}{\partial x_{j}}\left(A_{i j} \frac{\partial \bar{C}}{\partial x_{j}}\right)+q
$$


Fazendo coincidir os eixos principais do tensor $A_{i j}$ com os eixos horizontal e vertical do sistema de coordenadas cartesianas para uma descrição aproximada da difusão turbulenta no oceano, então, $i=j$, isto é, o coeficiente de difusão turbulenta será $A_{j j}$.

EQUAÇÃO DO BALANÇO ENERGETTICO

Substituindo na equação 26 a propriedade $\bar{C}$ pela quantidade de calor $Q$, e, portanto $\mathrm{B}=\mathrm{Q}=\mathrm{mcT}, \mathrm{b}=\mathrm{cT}$ e $\overline{\mathrm{C}}=\rho \mathrm{cT}$, onde $\mathrm{c}$ é o calor específico da água do mar. Essa propriedade (Q) é considerada para propósitos práticos da oceanografia como uma propriedade conservativa, uma vez que o calor dissipado por processos físicos, químicos e biológicos podem ser desprezíveis.

Como a densidade é, em geral, um pouco maior do que 1,0 e o calor específico ligeiramente menor que 1,0 , para simplificar faz-se $\rho c=1$, resultando:

$$
\frac{\partial T}{\partial t}+\frac{\partial T \bar{V}_{i}}{\partial x_{i}}=A_{j j} \frac{\partial^{2} T}{\partial x_{j}{ }^{2}}=A_{j j} \nabla^{2} T
$$

Integrando essa equação sobre um determinado elemento de volume, 1imitado por uma superfície fechada s:

$$
\int_{V} \frac{\partial T}{\partial t} d V+\int_{v} \frac{\partial T \bar{V}_{i}}{\partial x_{i}} d V=\int_{v} A_{j j} \nabla^{2} T d V\left[\begin{array}{lll}
c a 1 & T^{-1}
\end{array}\right]
$$

Aplicando o Teorema da divergência à segunda parcela do primeiro membro, resulta:

$$
\int_{v} \frac{\partial T}{\partial t} d V=-\int_{S} T \bar{V}_{i} n_{i} d S+\int_{v} A_{j j} \nabla^{2} T d V\left[\begin{array}{lll}
c a 1 & T^{-1}
\end{array}\right]
$$

Analisando os termos acima, conclui-se que a integral de volume da taxa de variação local da quantidade de calor é igual a integral do fluxo de 
calor através da superfície S devido ao transporte da corrente (efeito advectivo), mais a integral de volume da taxa de variação da concentração de calor devido aos efeitos de difusão turbulenta.

Para se levar em conta as trocas de energia que decorrem dos processos de interação ar-mar, supõe-se que o volume $\mathrm{V}$ seja uma coluna de água com superfície livre. Neste caso, devemos acrescentar ao segundo membro da equação 29 as parcelas seguintes, que representam as principais fontes e sumidouros de energia:

$$
q=R \pm Q_{s} \pm Q_{e}
$$

onde: $R$ é o balanço de radiação na superfície do mar; $Q_{S}$ é o calor trocado entre a superfície do mar e a atmosfera; $Q_{e}$ é a variação de calor da superfície do mar devido à evaporação e à precipitação.

Portanto, a equação geral de conservação para uma coluna de água com superfície livre é dada por:

$$
\int_{V} \frac{\partial T}{\partial t} d V=-\int_{S} T \bar{v}_{i} n_{i} d S+\int_{v} A_{j j} \nabla^{2} T d V+R \pm Q_{S} \pm Q_{e}
$$

Dentre outros fluxos de energia, que por serem muito pequenos em comparação àqueles incluídos na equação 31 são em geral desprezíveis, pode-se citar: a condução de calor, através do fundo do oceano, do interior da terra; calor produzido por processos químicos e biológicos; e, desintegração radioativa na āgua do mar.

EQUAÇÃO DO BALANÇO DO SAL

Se a propriedade cuja concentração a se estudar é a salinidade, que é intensiva $(B=b=S$ e $\bar{C}=\rho S$ ) e conservativa $(q=0)$, então a equação de conservação será dada por: 


$$
\frac{\partial \rho S}{\partial t}+\frac{\partial \rho S \bar{v}_{i}}{\partial x_{i}}=A_{j} j \nabla^{2} \rho S\left[\mathrm{ML}^{-3} \mathrm{~T}^{-1}\right]
$$

Para que se introduza, sem as dificuldades dimensionais, os processos de interação ar-mar, evaporação (E) e precipitação (P), normalmente medidos em unidades de comprimento, isto é, em alturas de água evaporada ou precipitada, quando uma coluna de água com superfície livre, for considerada, assume-se que $\rho=$ cte., e divide-se ambos os membros da equação 32 pelo produto $\rho \mathrm{S}_{\mathrm{r}}$, onde $\mathrm{S}_{\mathrm{r}} \mathrm{e}$ o valor de salinidade constante de referência. Logo,

$$
\frac{1}{s_{r}} \frac{\partial S}{\partial t}+\frac{1}{s_{r}} \frac{\partial S \bar{v}_{i}}{\partial x_{i}}=\frac{1}{s_{r}} A_{j j} \nabla^{2} S\left[T^{-1}\right]
$$

Analogamente à discussão da equação do balanço energético, integrando a equação 33 sobre um volume $\mathrm{V}$ constituída de uma coluna de água com superfície livre, resulta:

$$
\int_{v} \frac{1}{S_{r}} \frac{\partial S}{\partial t} d V=-\iint_{S} \frac{S \bar{V}_{i} n_{i}}{S_{r}} d S+\int \frac{A_{j j}}{S_{r}} \nabla^{2} S d V+(E-P)\left[L^{3} T^{-1}\right]
$$

onde: (E - P) representa a taxa de variação da diferença entre os volumes de àgua evaporada e precipitada.

0 primeiro membro da equação 34, representa a taxa de variação local e relativa do conteúdo de āgua doce que è o responsável pelas variações da salinidade, e, as duas primeiras parcelas do segundo membro, representam as variações relativas do conteúdo de água doce devido ao transporte advectivo e de difusão turbulenta, respectivamente.

\section{RESULTADOS EXPERIMENTAIS}

Como se viu anteriormente, os primeiros membros das equações de conservação de calor (eq. 31) e de sal (eq. 34), representam variações de calor 
armazenado e de água doce, responsāveis pelas variações da temperatura e da salinidade, respectivamente. Embora essas equações não sejam utilizadas do ponto de vista quantitativo, devido à falta de conhecimento de:

a) dos componentes de velocidade $\left(\overline{\mathrm{V}}_{i}\right)$;

b) dos coeficientes $A_{i j}$;

c) das quantidades, que representam as fontes ou sumidouros da propriedade na superfície do mar;

os resultados experimentais permitem inferir, do ponto de vista qualitativo, a preponderância de uma ou de outra das parcelas ( $a, b, c)$ intervenientes nas equações de conservação apresentadas.

DISTRIBUIÇÃO DAS PROPRIEDADES NA SUPERFICIE E A 25 m DE PROFUNDIDADE

\section{PRIMEIRO PERTODO}

(17 de agosto-11:30 h a 18 de agosto-24:00 h)

0 primeiro período de observações foi executado num intervalo de tempo de aproximadamente, trinta e seis horas. As Figuras 8-9, representam as distribuições de temperatura $(\mathrm{T})$, salinidade $(\mathrm{S})$, densidade $\left(\sigma_{\mathrm{T}}\right)$, observando-se os seguintes intervalos de variação dessas propriedades: $21,5<\mathrm{T}<22,5^{\circ} \mathrm{C}$, $34,0<\mathrm{S}<36,2^{\circ} /$ oo e $24,0<\sigma_{\mathrm{T}}<24,8$, respectivamente.

A situação, na região costeira à distâncias da costa menores do que $15 \mathrm{mn}$ e ao sul de Cabo Frio, era bastante uniforme, com águas quase isotérmicas $\left(21,5<\mathrm{T}<21,8^{\circ} \mathrm{C}\right)$, e isohalinas $\left(\mathrm{S} \approx 35,0^{\circ} / 00\right)$, pouco densas $\left(\sigma_{T} \approx 24,0\right)$, que são características de águas costeiras. Ao sul da Baía de Guanabara, localiza-se um núcleo com máximos de temperatura $\left(\mathrm{T} \approx 22,5^{\circ} \mathrm{C}\right.$ ) e de salinidade $(S \approx 36,2 \%$ ), que caracterizam a presença de águas Tropicais.

Admitindo-se que as observações de vento da estação meteorológica da Companhia Nacional da Ācalis sejam representativas para a região costeira investigada, observa-se que prevaleceram, antes do início das observações oceanográficas, ventos de ESE e WSW, com velocidades médias horárias entre 


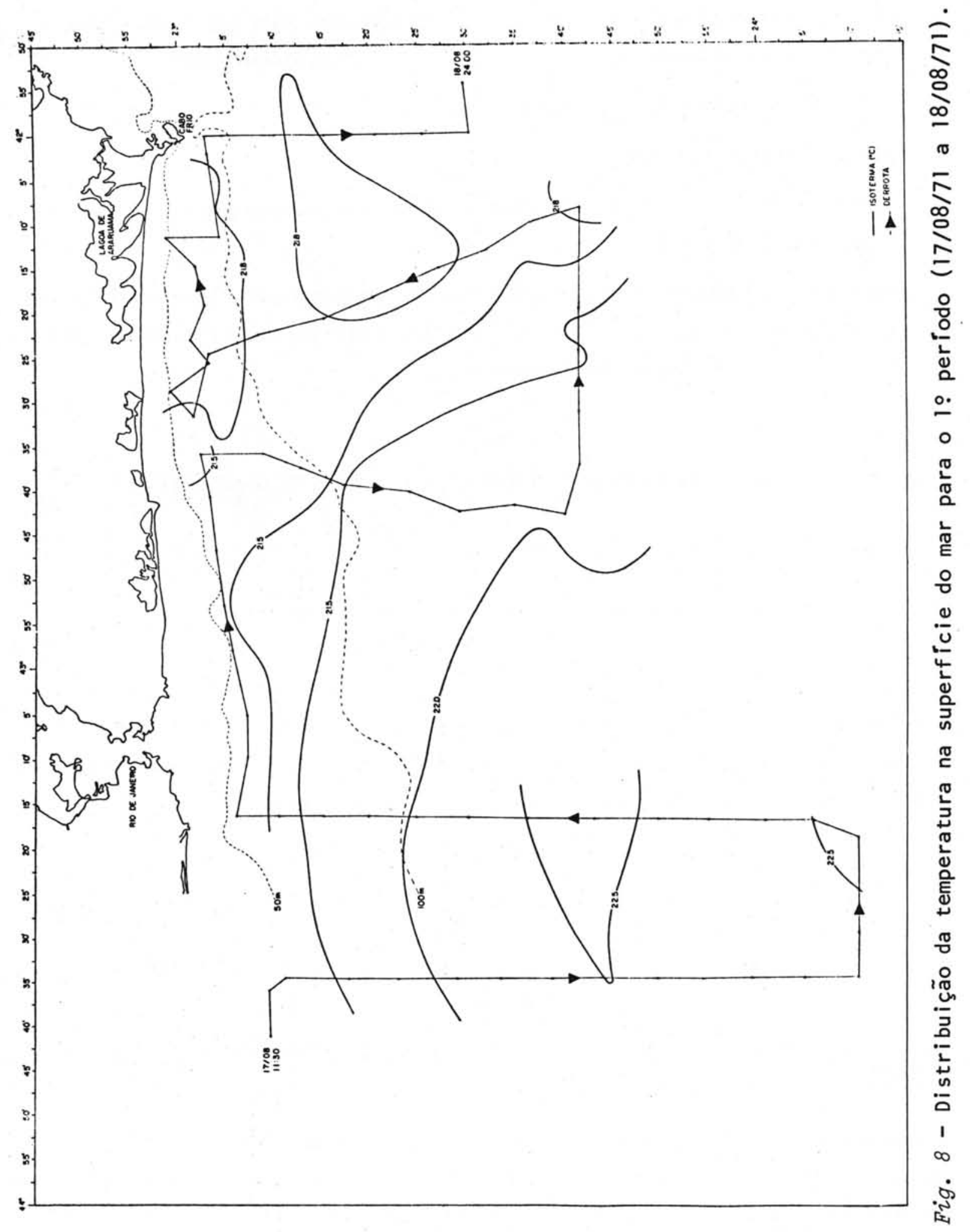




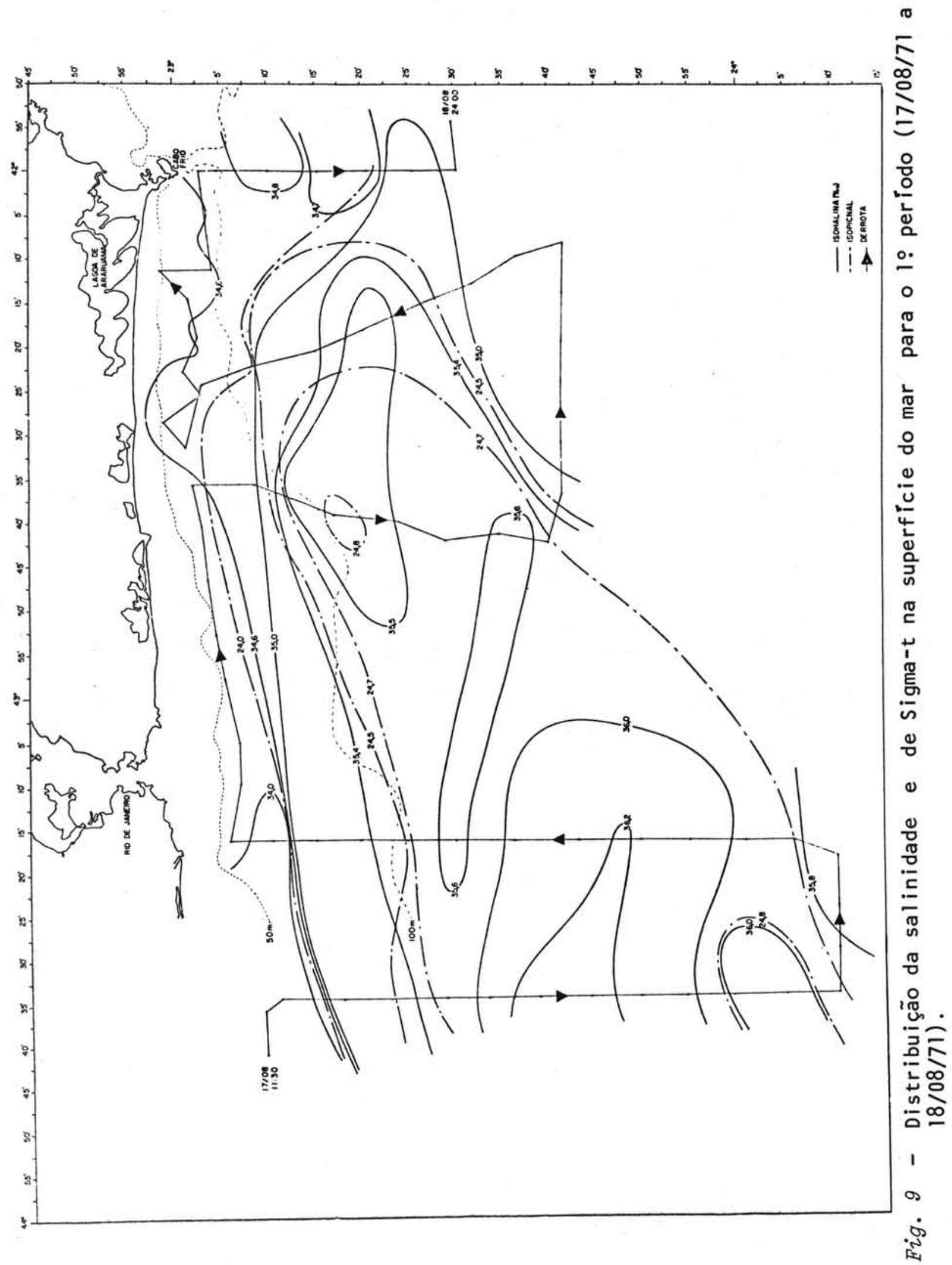


0 e $4 \mathrm{~m} / \mathrm{s}$, (Fig. 5). A partir das 15:00 horas do dia 17 de agosto e, portanto, jā no início das medições oceanográficas que se iniciaram a oeste da Baía de Guanabara (Figs 8-9), a direção do vento mudou para NE, E e ENE, com velocidades médias horärias entre 2 e $9 \mathrm{~m} / \mathrm{s}$ (Fig. 5).

Com relação às propriedades medidas neste primeiro período, não foi observada nenhuma anomalia, apesar da mudança da direção do vento.

\section{SEGUNDO PERTODO}

(19 de agosto-22:00 h a 20 de agosto-12:00 h)

Nas Figuras 10-11, apresenta-se as condições do segundo período, que foi realizado depois de decorrido um intervalo de tempo de, aproximadamente, vinte e quatro horas do término do período anterior. Anomalias nas distribuições da temperatura e salinidade são agora indicadas pelo decréscimo da

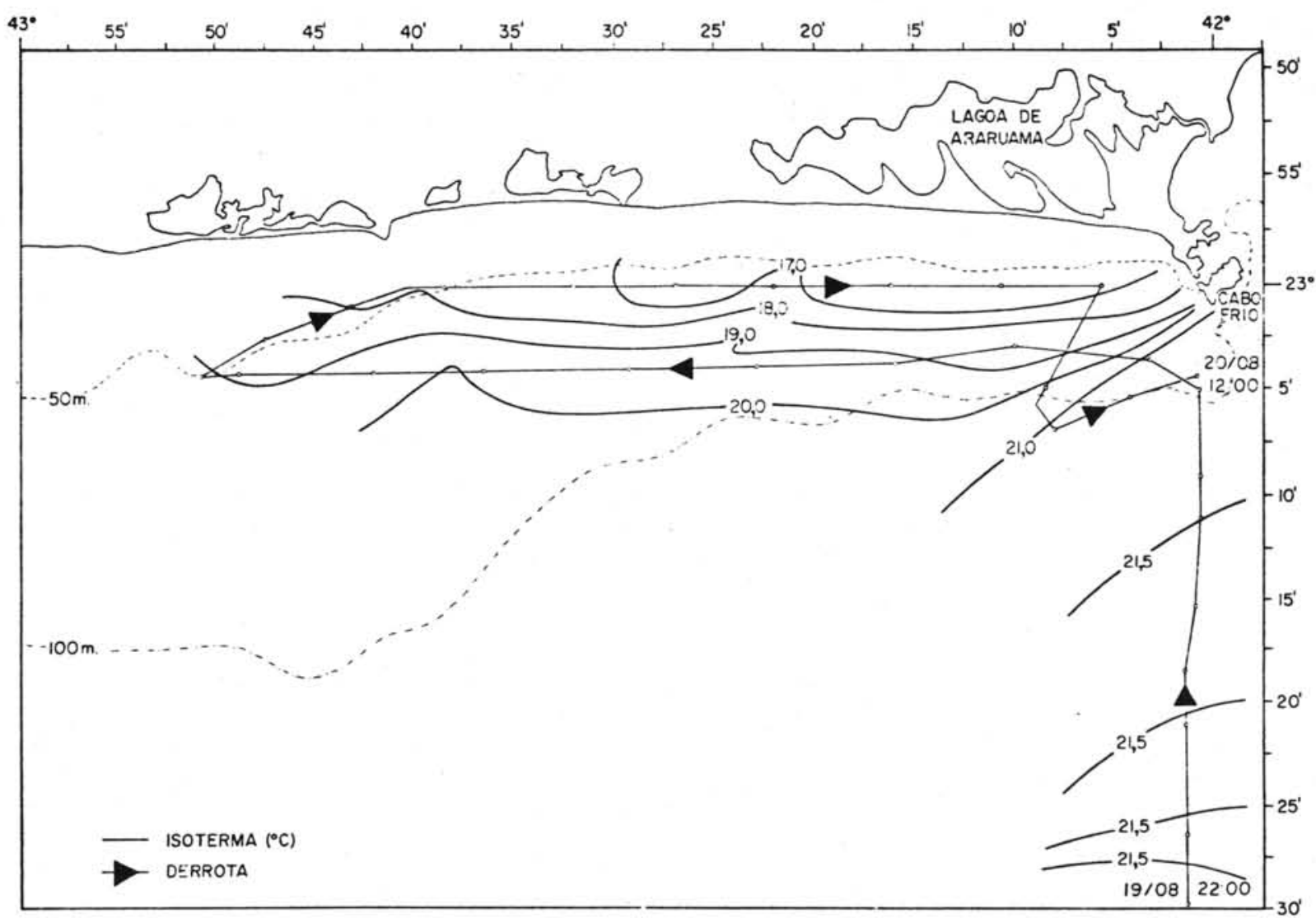

Fig. 10 - Distribuição da temperatura na superfície do mar para o 2: período $(19 / 08 / 71$ a $20 / 08 / 71)$. 


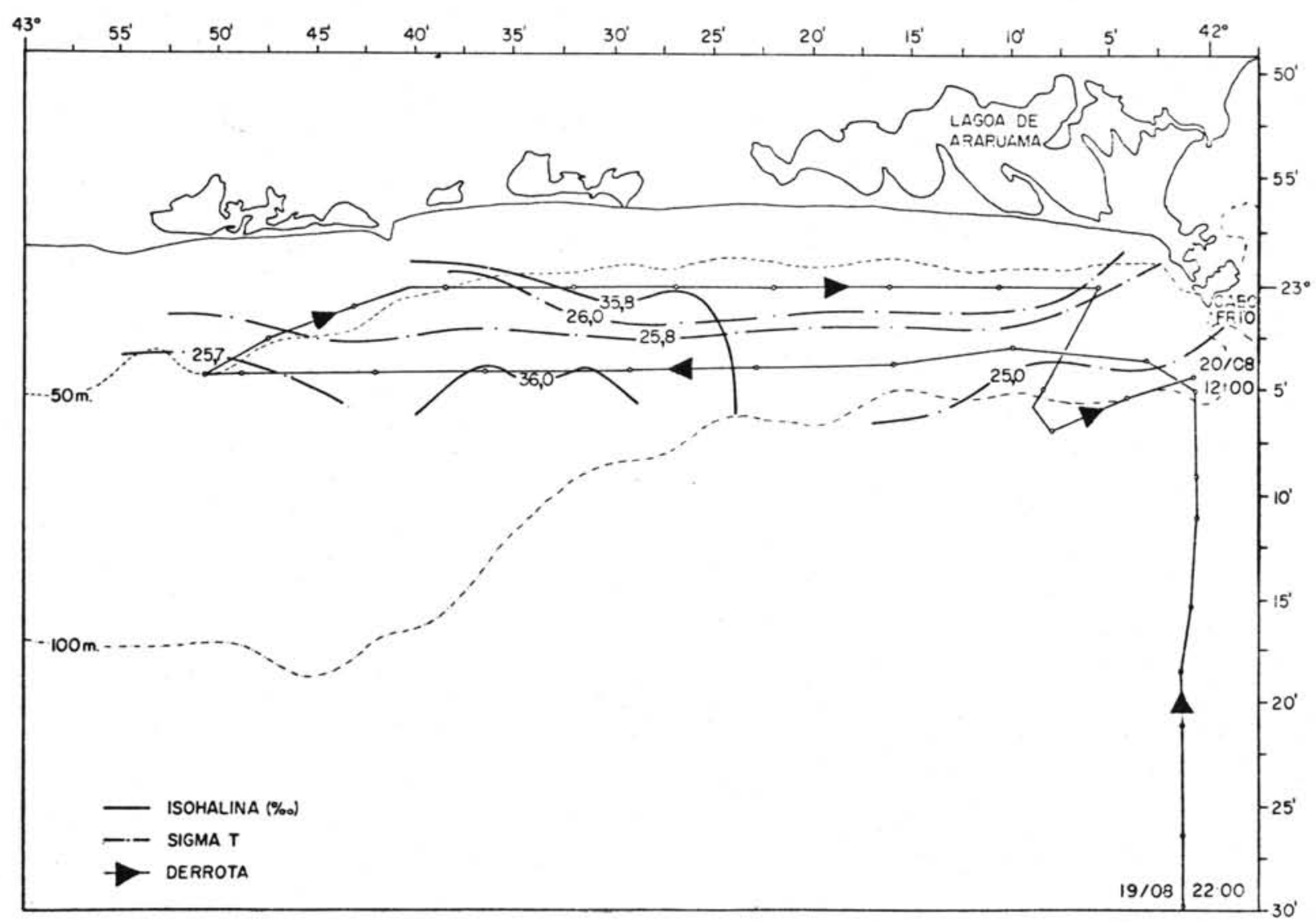

Fig. 11 - Distribuição da salinidade e de Sigma-t na superfície do mar para o 2 : período $(19 / 08 / 71$ a $20 / 08 / 71)$.

temperatura e aumento da salinidade nas proximidades da costa de aproximadamente $5,0^{\circ} \mathrm{C}$ e $1,0^{\circ} \%$, respectivamente. Nesta região, observa-se, agora, a ocorrência de um mínimo de temperatura $\left(T \approx 17,0^{\circ} \mathrm{C}\right.$ ) isolado, associado à salinidade de aproximadamente $35,8 \%$; estas características indicam claramente a presença, nessa região costeira, de āguas de origem subtropical, que segundo Sverdrup et al. (1942), têm sua origem na região da Convergência Subtropica1.

A comparação das distribuições de densidade, para esses dois primeiros períodos de observação (Figs 9 e 11), indica que as águas costeiras e pouco densas $\left(\sigma_{\mathrm{T}} \approx 24,0\right)$, foram substituídas por águas mais densas $\left(\sigma_{\mathrm{T}} \approx 26,0\right) \mathrm{e}$ oriundas de camadas mais profundas.

Durante este período de observações, predominaram ventos de $\mathrm{N}$ e NNE (Fig. 5). Se a variação da estrutura térmica foi devida à mudança da direção 
do vento (ESE e WSW para NE, E e ENE), então, este efeito fez-se sentir após, aproximadamente, quarenta e oito horas.

\section{TERCEIRO PERTODO}

(20 de agosto-15:00 h a 21 de agosto-11:00 h)

Este período de observações, foi iniciado com um intervalo de tempo de aproximadamente três horas do período anterior e permitiu um mapeamento detalhado da estrutura térmica, halina (jā apresentada por Ikeda et al., 1971) e de densidade (Figs 12-13).

As āguas costeiras, com temperatura menor do que $20,0^{\circ} \mathrm{C}$, ocupam uma ārea maior do que a observada no período anterior (Fig. 10), o que demonstra que a influência do estágio inicial do ressurgimento de águas de camadas mais profundas tem sua influência propagada, graças aos processos advectivos e

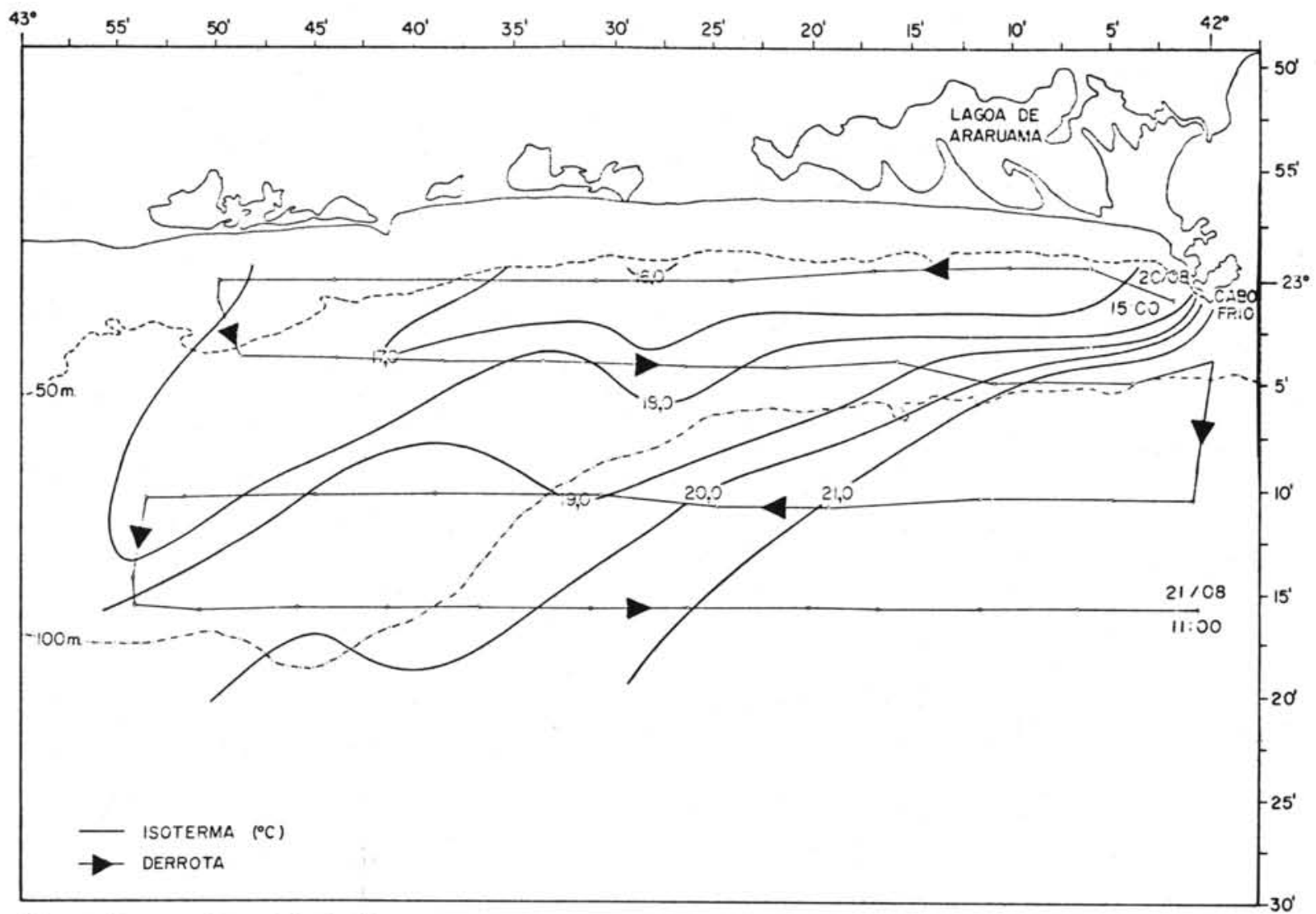

Fig. 12 - Distribuição da temperatura na superfície do mar para o 3 ? período $(20 / 08 / 71$ a $21 / 08 / 71)$. De acordo com Ikeda et al. (1971). 


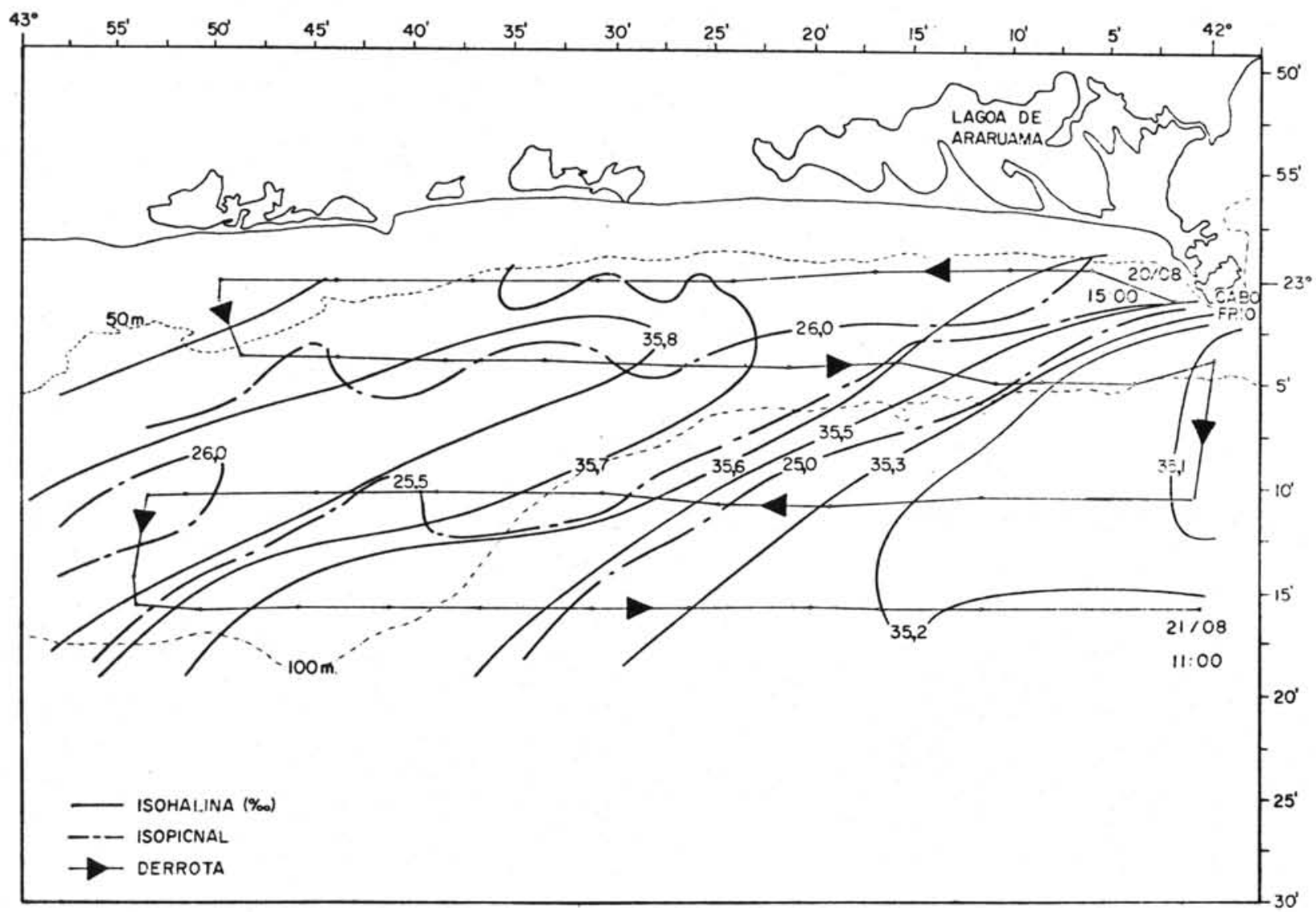

Fig. 13 - Distribuição da salinidade e de Sigma-t na superfície do mar para o 3 ? período $(20 / 08 / 71$ a $21 / 08 / 71)$. De acordo com Ikeda et al. (1971).

difusivos, para a região oceânica adjacente. Essa rápida renovação das águas costeiras, que ocorreu em aproximadamente 60 horas e cujas estruturas térmicas e halinas apresentam núcleos isolados de baixa temperatura e alta salinidade, nos permite sugerir a preponderância dos processos advectivos e difusivos em alterar as distribuições da temperatura e da salinidade.

As características térmicas e halinas das águas presentes nas proximidades da costa (Figs 12-13), permitem classificá-1as como águas de origem subtropica1.

Relativamente à densidade, (Fig. 13), observa-se que essa propriedade dependente da água do mar, decresce com a distância à costa, indicando assim, que as águas costeiras com $\sigma_{\mathrm{T}} \approx 26,0$ são oriundas de camadas profundas. 


\section{QUARTO PERTODO}

(21 de agosto-13:00 h a 23 de agosto-11:00 h)

Durante este período de observações, iniciado com um intervalo de tempo de duas horas do período anterior, o sensoreamento contínuo com o termosalinógrafo, foi interrompido aproximadamente a cada 10 milhas náuticas, para a execução de uma rede de estações hidrográficas, com o objetivo de medir as propriedades temperatura e salinidade desde a superfície até as proximidades do fundo. Cada estação hidrogräfica teve a duração de cerca de trinta minutos, e as medições de superfície foram utilizadas para a verificação do registro analógico, como indicado na Figura 2.

Na distribuição térmica na superfície (Fig. 14), pode-se notar na região costeira dois núcleos isolados com temperaturas contrastantes. 0 núcleo máximo de temperatura $\left(\mathrm{T} \approx 20,0^{\circ} \mathrm{C}\right.$ ) ao largo da Baía de Guanabara está associado a um núcleo de mínimo de salinidade $\left(\mathrm{S} \approx 35,3^{\circ} \%\right.$ o, tal como se observa na Figura 15. Um mínimo com esse mesmo teor de sal, localizado nessa mesma região, foi encontrado por Magliocca et al. (no prelo) em fevereiro de 1971, tendo sido explicado como influência residual das águas de baixa salinidade que fluem, durante a baixa-mar, para a região costeira. 0 núcleo com o mínimo de temperatura $\left(\mathrm{T} \approx 15,5^{\circ} \mathrm{C}\right)$, que se localiza ao largo da Ponta de Saquarema, está associado à águas com salinidade entre 35,7 e $35,8 \%$, o que indica a origem subtropical dessa massa de água.

Na distribuição da densidade na superfície (Fig. 15), observa-se, na região de temperatura mínima, a ocorrência de águas mais densas, que se identificam pelo núcleo isolado de $\sigma_{\mathrm{T}} \approx 26,2$. Evidencia-se, uma vez mais, a presença de movimentos ascendentes nessa região costeira, cuja influência faz-se sentir numa área mais ampla do que a observada no período anterior e a SW do núcleo de ressurgência.

A comparação das observações de vento realizadas a bordo do N/Oc. "Prof. W. Besnard" durante estações hidrográficas (Fig. 3), com as observações locais do vento, realizadas na estação meteorológica da Companhia Nacional de Ālcalis (Fig. 6), indicam a predominância dos ventos $\mathrm{N}$, NNE, NE e E, com velocidades entre 3 e $12 \mathrm{~m} / \mathrm{s}$, durante este período de observações. 


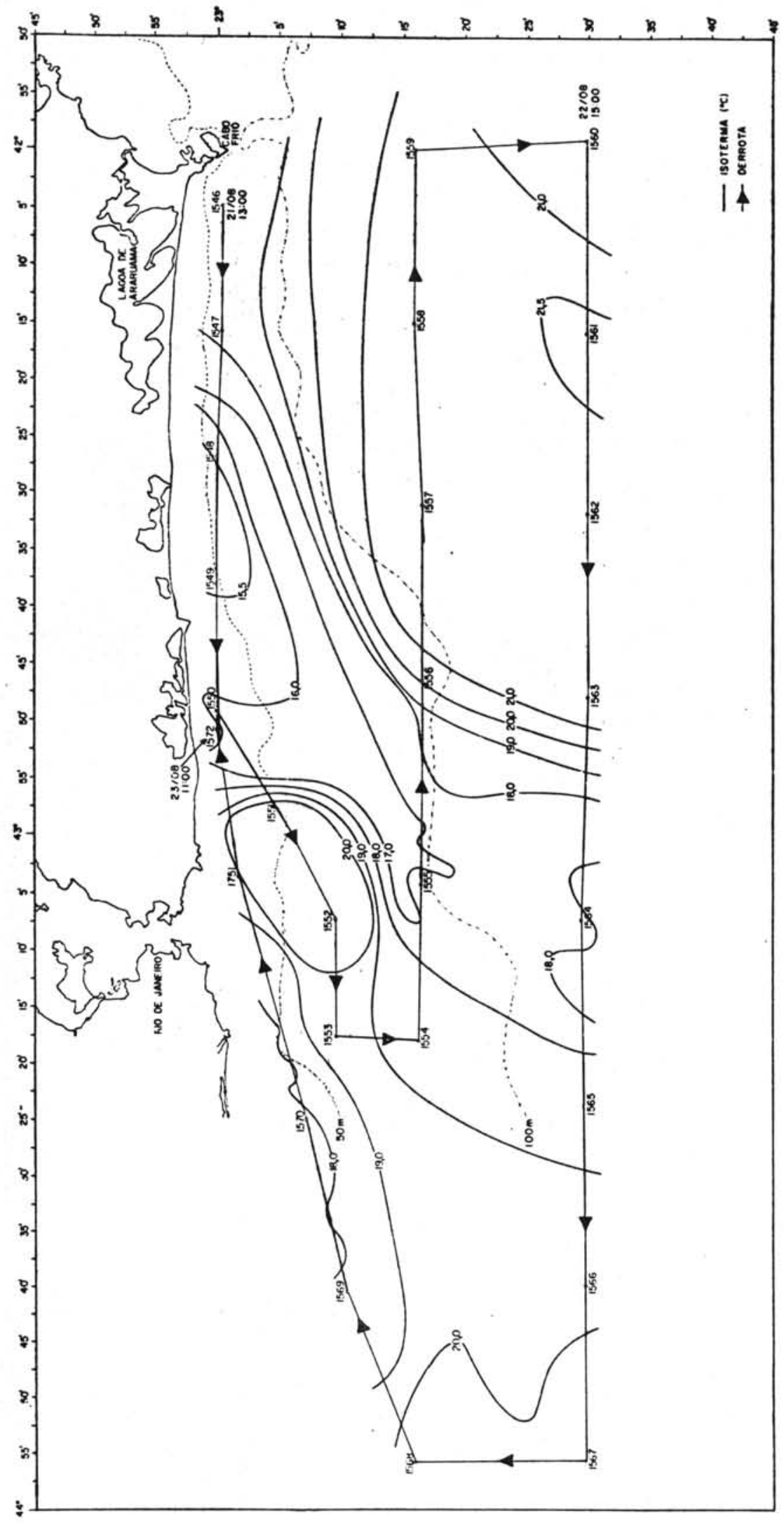

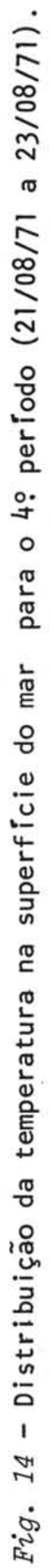



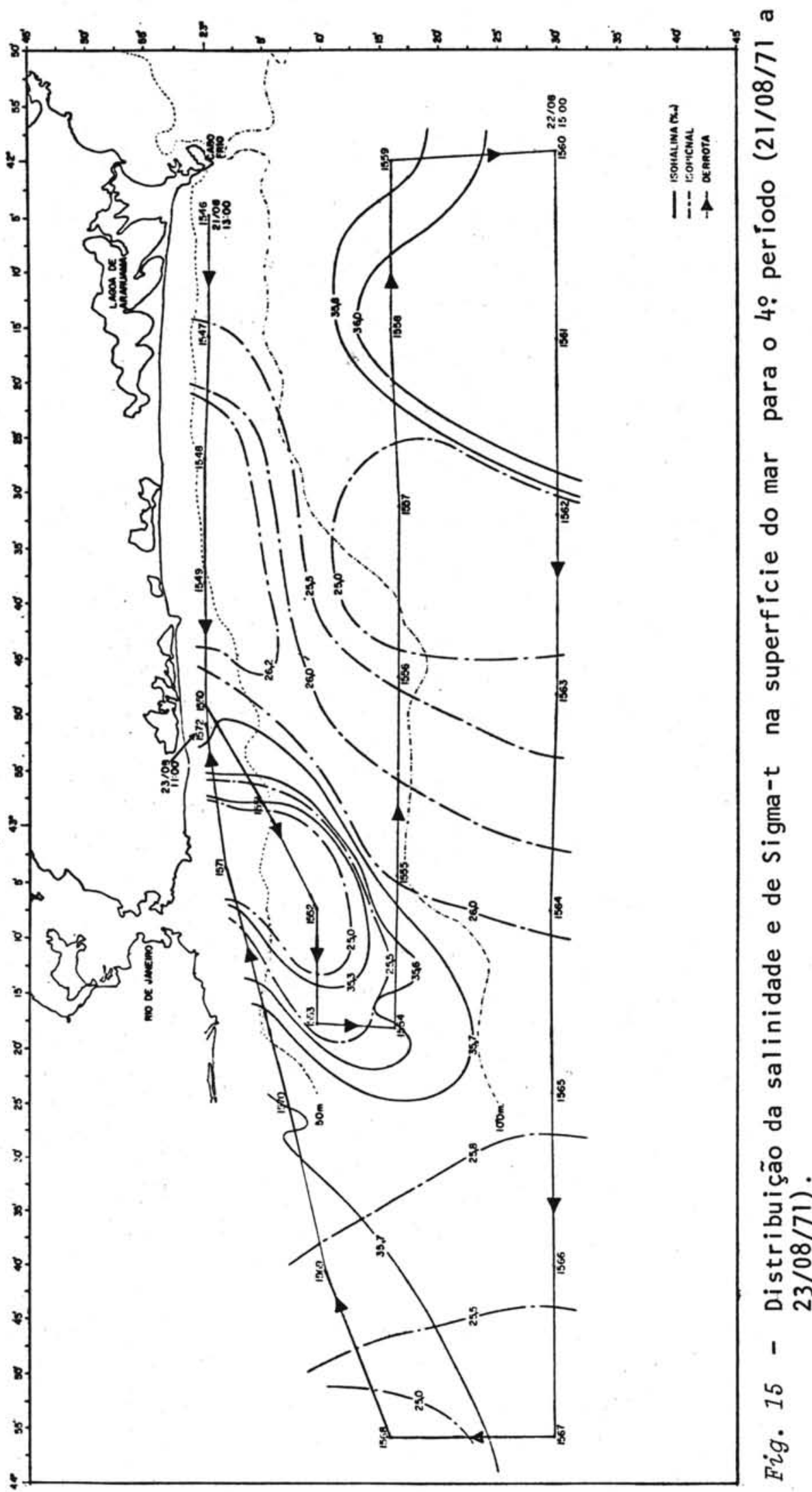
A estrutura térmica deste período de observações, construída com os dados discretos das estações hidrogräficas (Fig. 16), apresenta-se mais simplificada do que a correspondente estrutura obtida com os dados contínuos do termosalinógrafo (Fig. 14), não sendo possỉvel observar, na primeira Figura, os núcleos discutidos nos parágrafos anteriores. Destaca-se portanto, pela comparação dessas Figuras, a importância do registro contínuo em fornecer informações experimentais para estudos teóricos de fenômenos transitórios.

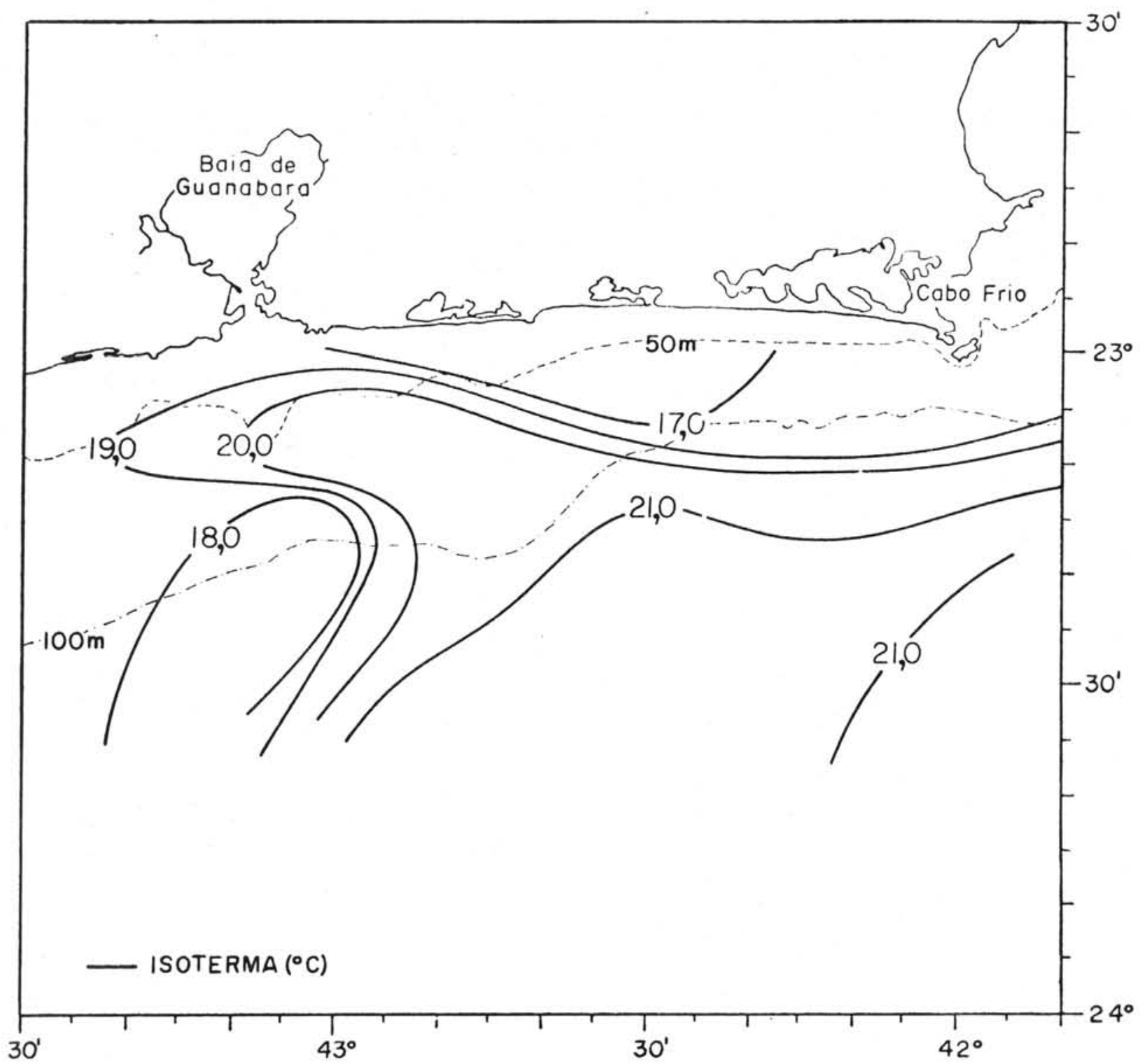

Fig. 16 - Distribuição da temperatura na superfície do mar para o 4 ? período $(21 / 08 / 71$ a $23 / 08 / 71)$, obtida com os dados das estações hidrogräficas. 
Para a profundidade de $25 \mathrm{~m}$, cuja estrutura térmica é apresentada na Figura 17 (construída com dados discretos), observa-se que os mínimos de temperatura $\left(\mathrm{T} \approx 15,0^{\circ} \mathrm{C}\right)$ ocorrem nas proximidades da costa, e que essa propriedade cresce com o aumento da distância à costa.

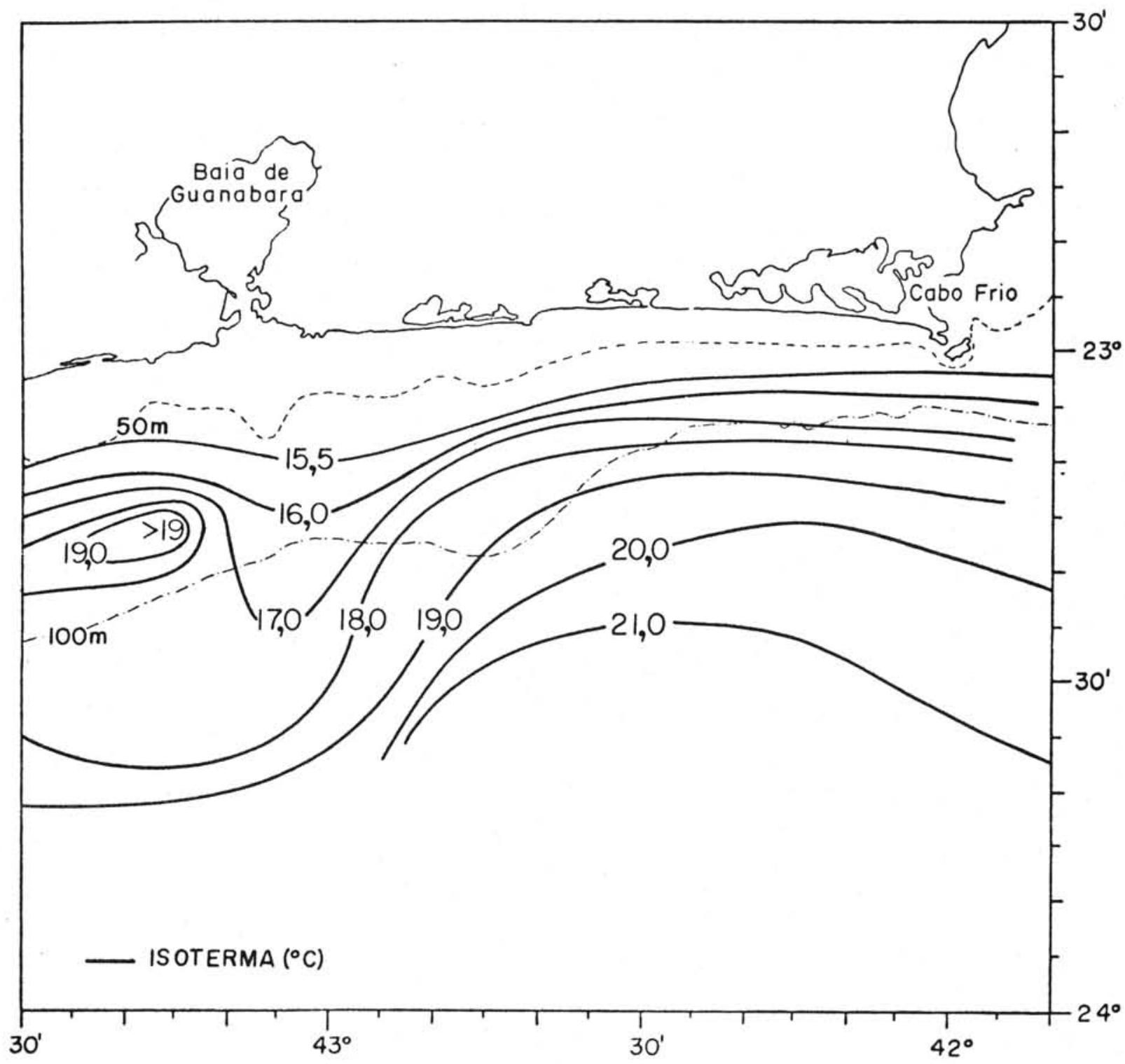

Fig. 17 - Distribuição da temperatura a $25 \mathrm{~m}$ de profundidade para o 4 ? período $(21 / 08 / 71$ a $23 / 08 / 71)$, obtida com os dados das estações hidrogräficas. 
QUINTO PERTODO

(23 de agosto-13:00 h a 24 de agosto-19:00 h)

Tal como no período anterior, o sensoreamento contínuo do termosalinógrafo foi interrompido para execução de uma rede de estações hidrográficas.

Como se pode observar, houve uma mudança bastante acentuada na distribuição das propriedades analisadas (Figs 18-19). A região onde ocorre as menores temperaturas $\left(15,0<\mathrm{T}<16,0^{\circ} \mathrm{C}\right)$, que estão associadas a àguas com salinidades entre 35,5 e $35,6^{\circ} \%$ e densidade $\sigma_{\mathrm{T}} \approx 26,3$, apresenta-se como uma faixa de āgua quase homogênea, faixa esta que se orienta na direção SW, e cujas propriedades caracterizam águas de origem subtropical. 0 mínimo de temperatura é agora observado a SE da Baía de Guanabara e a $15 \mathrm{mn}$ de distância da costa.

A leste dessa faixa, observa-se a ocorrência de um núcleo com salinidade maior do que $35,8 \%$, cuja influência faz-se observar até as proximidades da costa (Fig. 19).

A estrutura térmica de superfície obtida com os dados discretos é apresentada na Figura 20. A semelhança dessa estrutura com àquela obtida com dados contínuos (Fig. 18), leva a crer que o fenômeno, que provocou as anomalias na distribuição das propriedades, já estava atingindo o seu estado quase estacionário, o que não foi o caso do período anterior.

Com relação à distribuição da temperatura a $25 \mathrm{~m}$ de profundidade (Fig. 21), também obtida com dados discretos, notamos que as isotermas com $\mathrm{T}<17,0^{\circ} \mathrm{C}$ tendem a seguir a direção' do vento prevalescente (Fig. 6), cuja direção é $\mathrm{N}$ e NNE, com velocidade média horāria de $9 \mathrm{~m} / \mathrm{s}$. Esta característica da estrutura térmica não foi observada no período anterior (Fig. 17), o que indica que a influência advectiva da água de ressurgência, ao divergir da costa, se restringia aos primeiros metros da camada superficial, se estende agora até esta profundidade. Ao sul de Cabo Frio, observa-se a ocorrência de um núcleo de temperatura com $\mathrm{T}>20,0^{\circ} \mathrm{C}$, indicando a influência advectiva da Corrente do Brasil. 


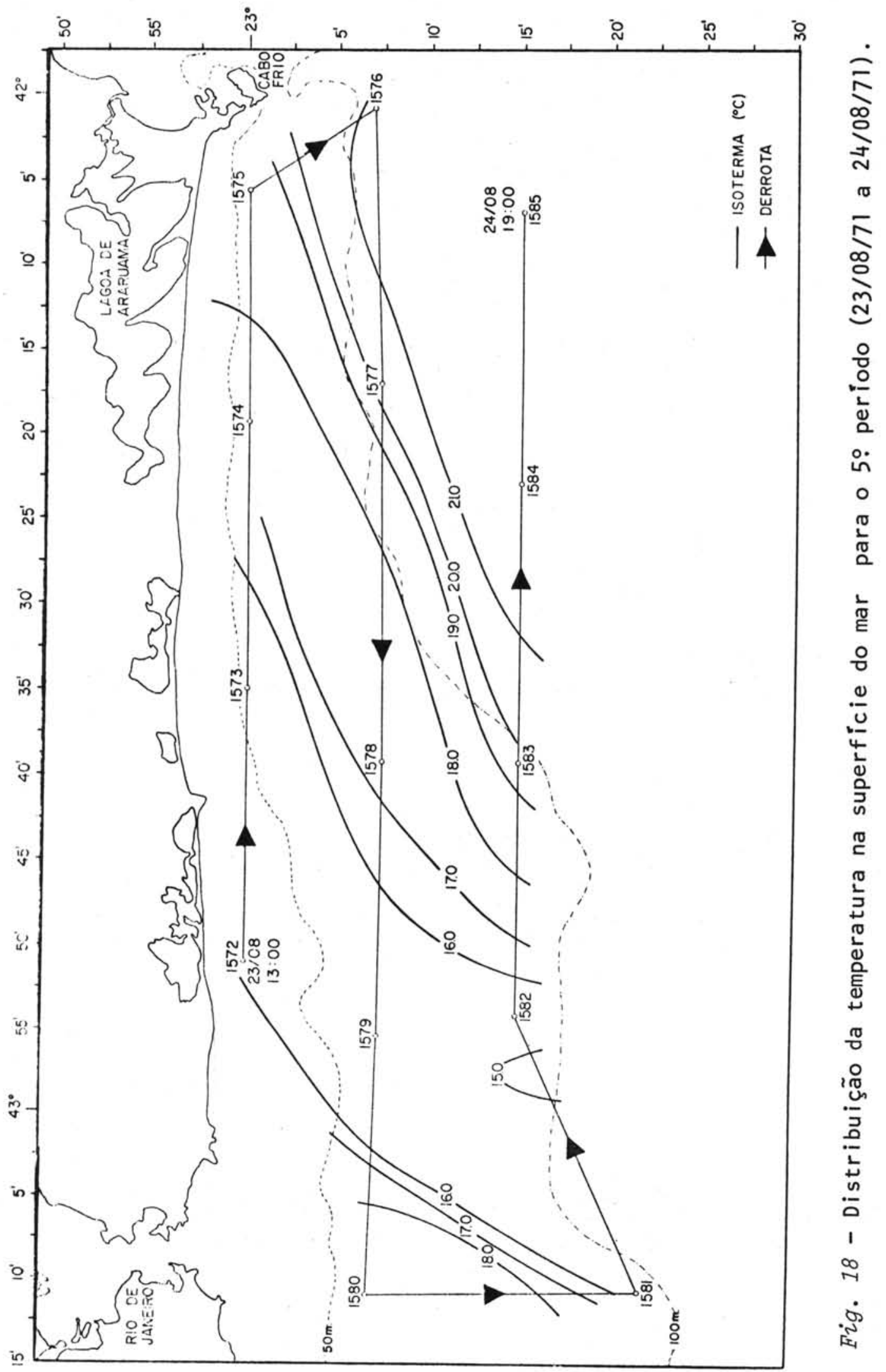




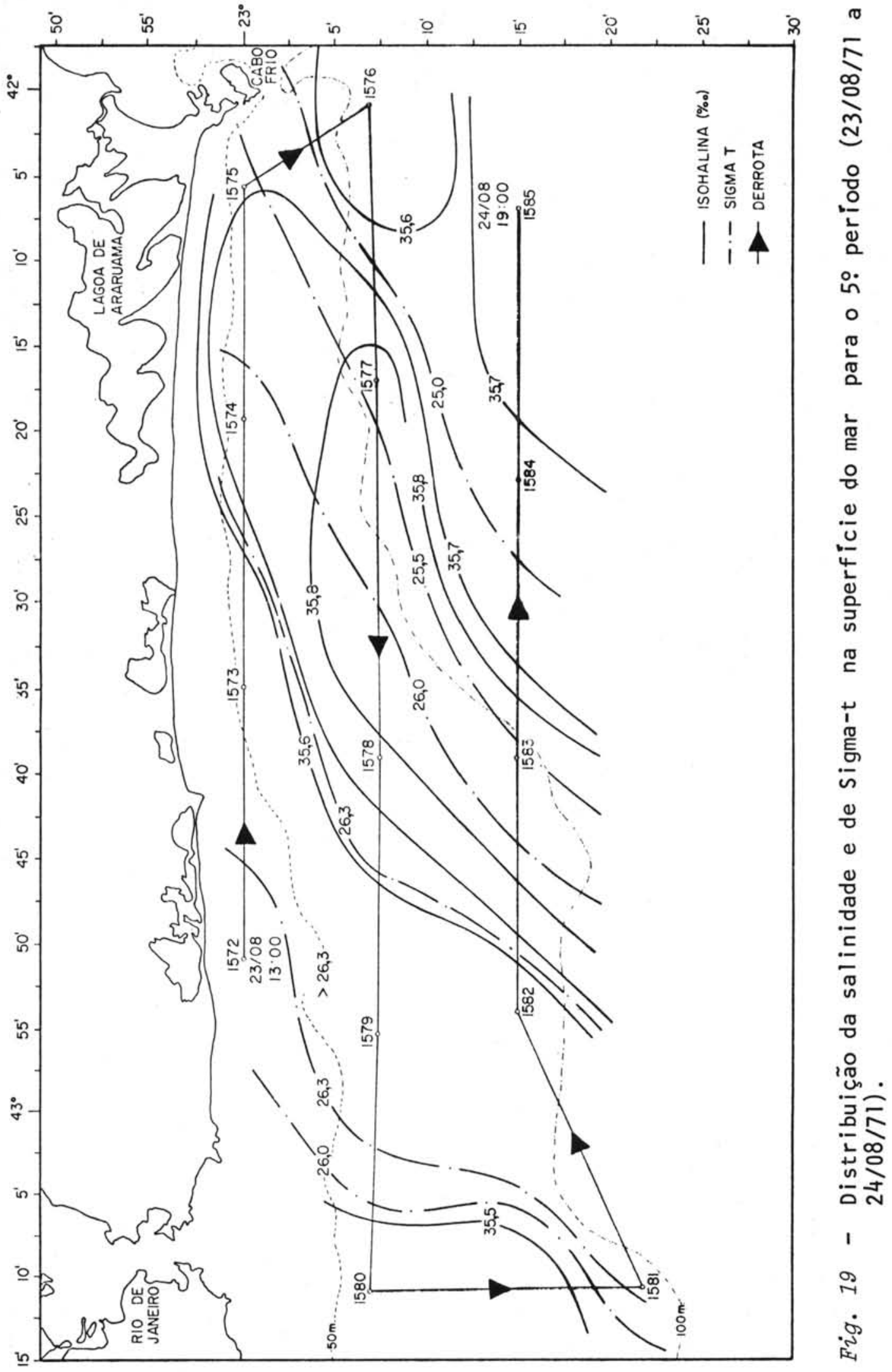




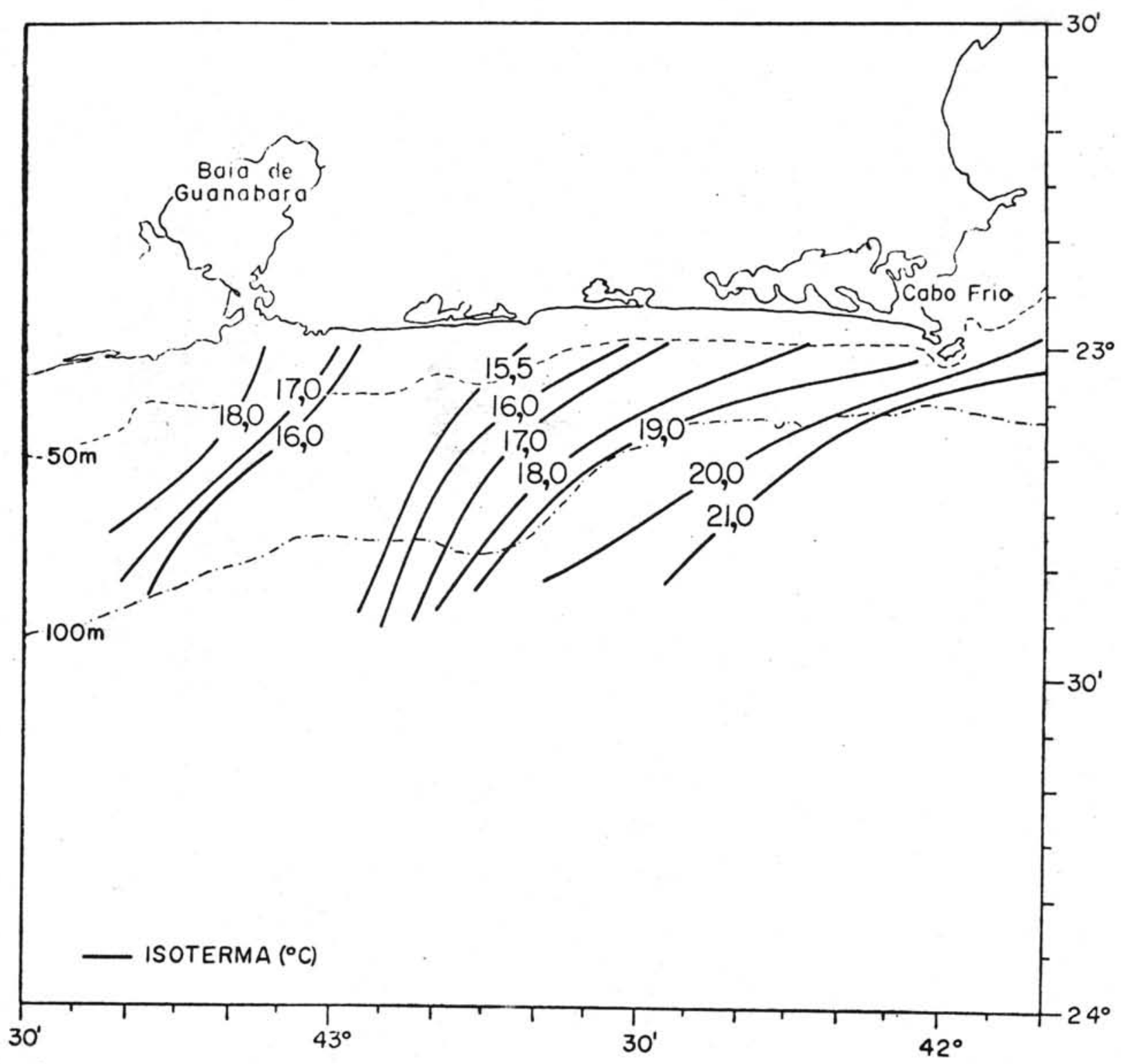

Fig. 20 - Distribuição da temperatura na superfície do mar para o 5 ? período (23/08/71 a $24 / 08 / 71)$, obtida com os dados das estações hidrogrä-

\section{SEXTO PERTODO}

(25 de agosto-00:30 h a 25 de agosto-14:00 h)

Este perỉodo abrange uma ārea de observações mais restrita (da longitude de $42^{\circ} 53^{\prime} \mathrm{W}$ até às proximidades da Ilha do Cabo Frio) em relação à área do período anterior (sul da Baía de Guanabara atē as proximidades da Ilha do 


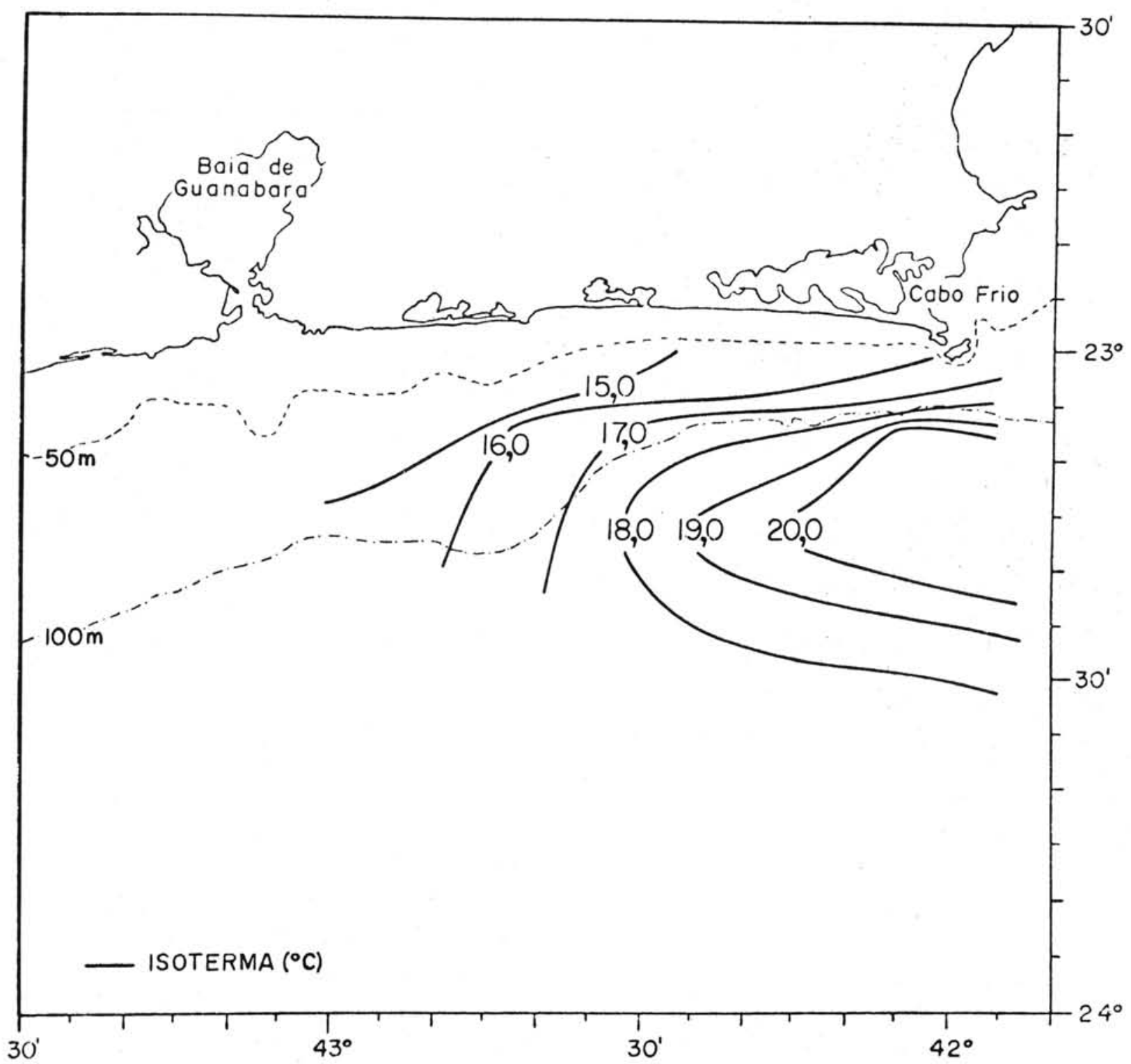

Fig. 21 - Distribuição da temperatura a $25 \mathrm{~m}$ de profundidade para o 5 ? período $(23 / 08 / 71$ a $24 / 08 / 71)$, obtida com os dados das estações hidrogräficas.

Cabo Frio), tendo sido iniciado com um intervalo de cinco horas após o tērmino do anterior.

A comparação dos dois períodos permite observar que as isotermas $\left(15,0<\mathrm{T}<21,0^{\circ} \mathrm{C}\right.$ ) (Fig. 22), as isohalinas $\left(35,6<\mathrm{s}<35,8^{\circ} / 00\right)$ e as isopicnais $\left(25,5<\sigma_{\mathrm{T}}<26,4\right)$ (Fig. 23), a oeste do mínimo de temperatura, permaneceram em estado quase estacionário. Entretanto, o mesmo não ocorre à 


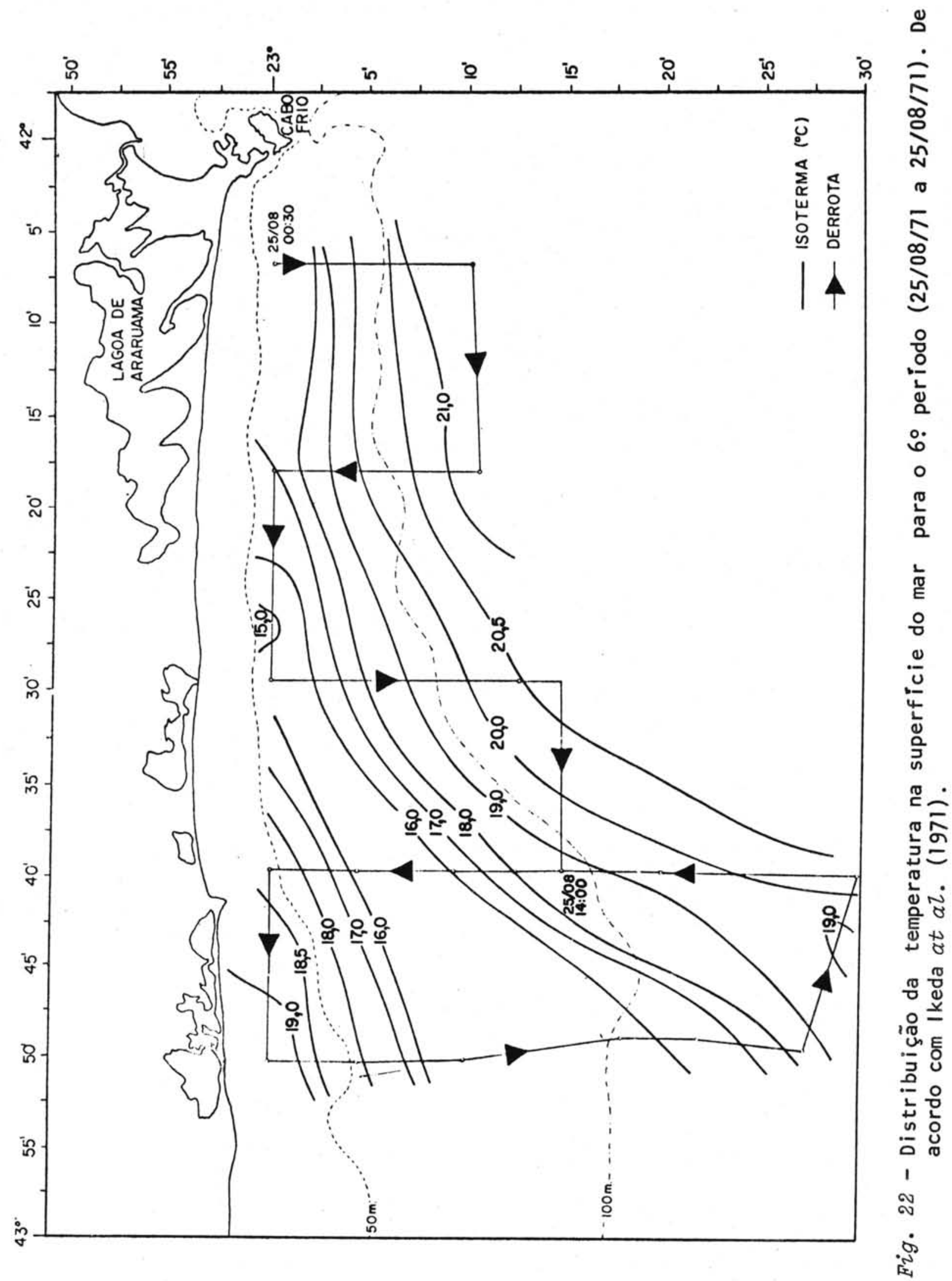




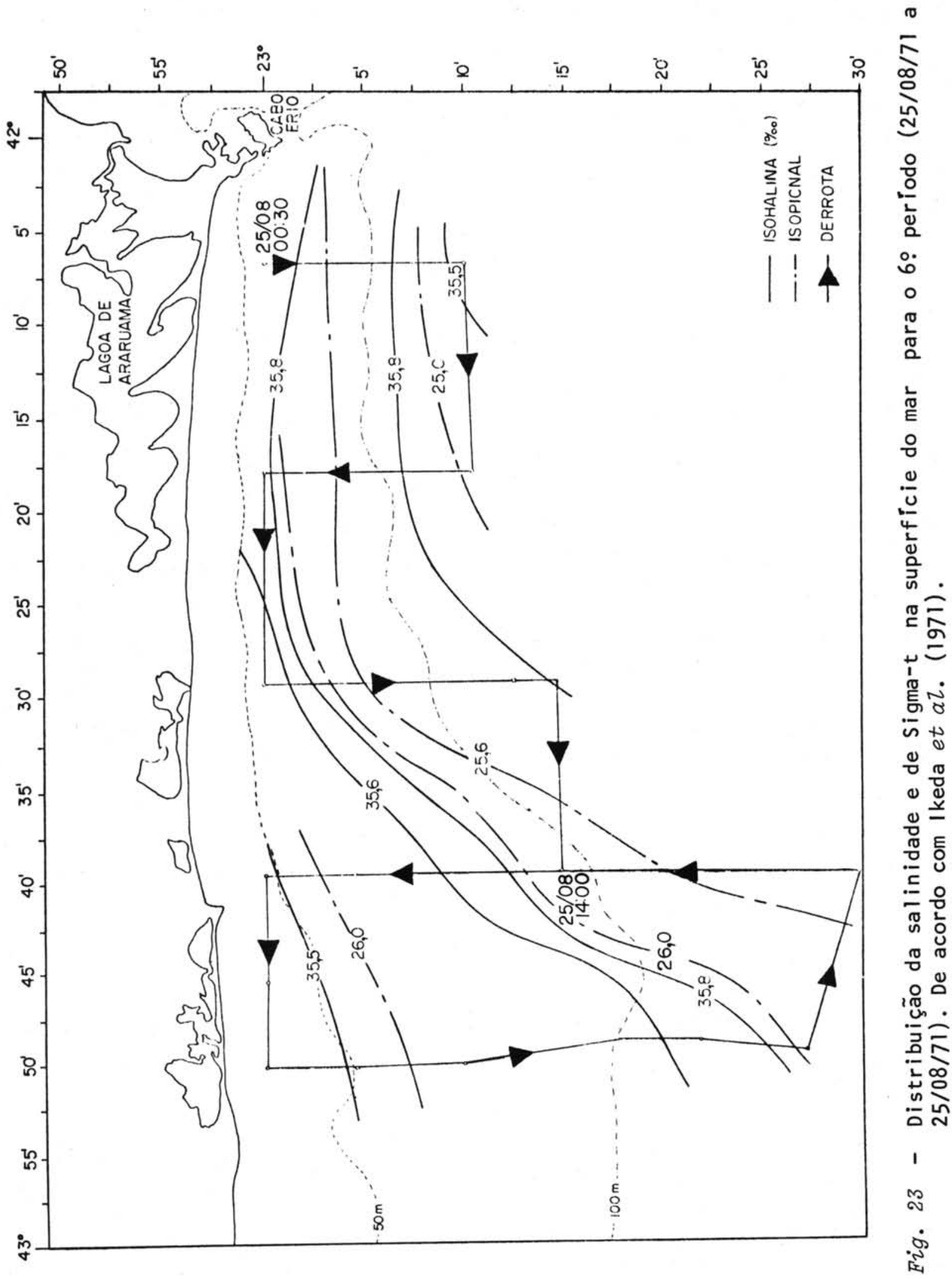


E (leste) desse mínimo e o deslocamento observado nas isolinhas dessa propriedade sugerem a advecção de águas costeiras para leste.

Esses deslocamentos, muito provavelmente, se originaram por influência da mudança da direção do vento. Isto foi realmente observado, conforme Figura 6, tendo o vento mudado de $\mathrm{N}$ e NNE, rondando no início do dia 25 por NNW, NW, WNW, até SSW e S.

\section{SETIMO PERTODO}

(25 de agosto-14:00 h a 26 de agosto-13:00 h)

Este período (Figs 24-25) foi iniciado imediatamente após o anterior, e a comparação dos resultados destes dois períodos permitem observar que não há deslocamentos das propriedades, e, assim, conseqüentemente, associar um estado quase estacionário na sua distribuição. Entretanto, uma característica não amostrada nos períodos anteriores é a influência das águas de origem tropical ( $>36,0^{\circ}$ oo) transportadas pela Corrente do Brasil, associadas à temperaturas superiores a $21,0^{\circ} \mathrm{C}$, que se observa ao sul da latitude de $23^{\circ} 25^{\prime} \mathrm{s}$.

Cerca de cinco dias após este ūitimo período de observações, as medições radiométricas da temperatura da água do mar realizadas a bordo de um helicóptero (Almeida et $a$ l., 1971b - fig. 34), indicaram a existência de acentuados gradientes horizontais de temperatura nas vizinhanças de Cabo Frio, que se acredita ser decorrentes de influências da estrutura térmica que ora se observa ao sul da Lagoa de Araruama (Fig. 24).

VARIAÇÃO DAS PROPRIEDADES OCEANOGRĀFICAS AO LONGO DE UMA SECÇÃO PARALELA Ā COSTA NA LATITUDE DE $23^{\circ} 00^{\prime} \mathrm{S}$

Na Figura 26 apresenta-se os registros 1, 2, 3 e 4, correspondentes aos dias 20, 21 e 23 de agosto, respectivamente, obtidos ao longo da secção paralela à costa e que está indicado no mapa inserido nessa Figura. Destes registros analógicos, observa-se que a temperatura e salinidade variam entre 


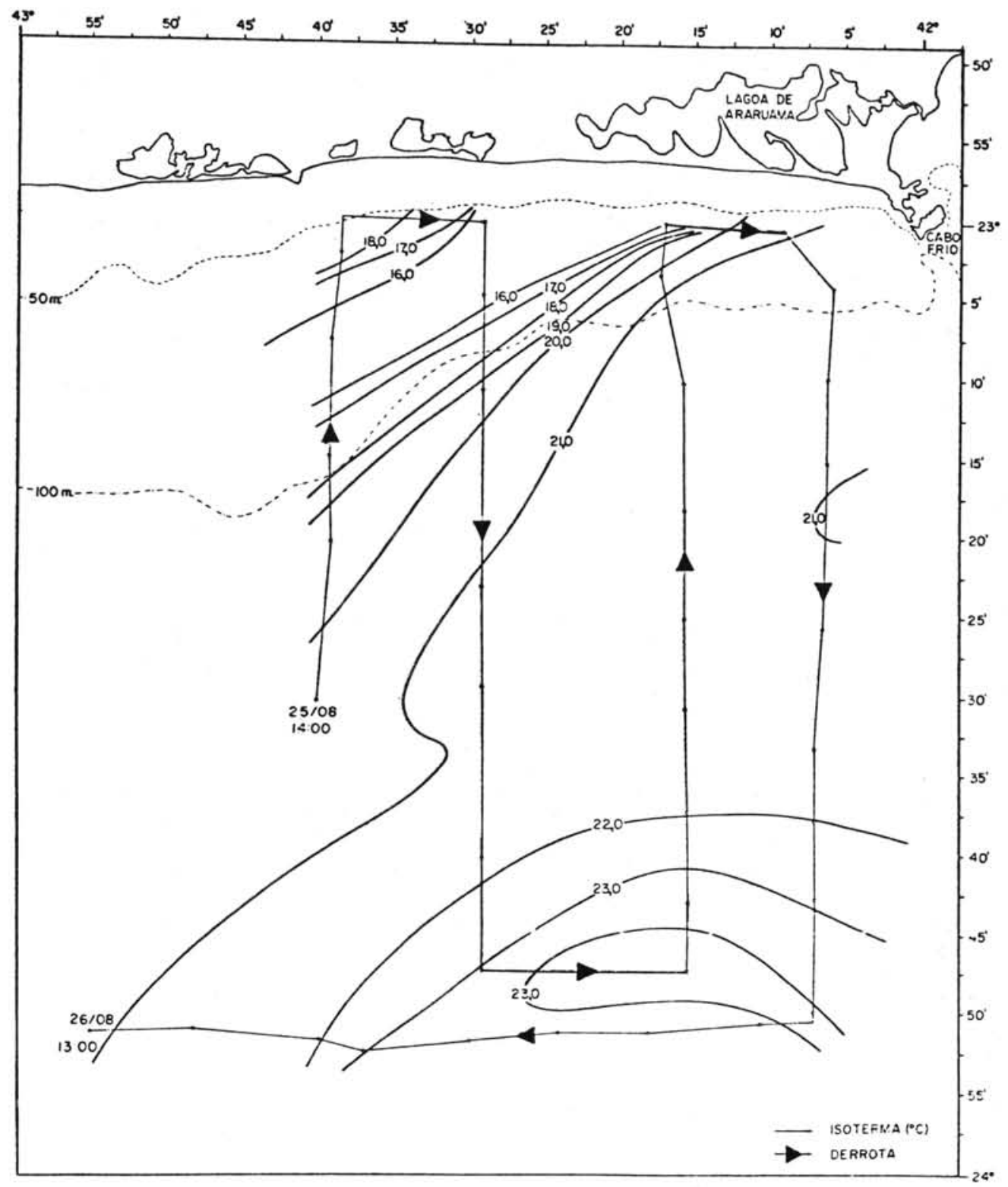

Fig. 24 - Distribuição da temperatura na superfície do mar para o 7 : período (25/08/71 a 26/08/71).

15,5 e $19,0^{\circ} \mathrm{C}$ e 35,4 e $35,8^{\circ} \%$, respectivamente, sendo estas propriedades características de águas de origem subtropical.

Nessa Figura há um ponto $P$ de cruzamento nos registros 1, 2 e 3, para um valor de temperatura igual a $17,5^{\circ} \mathrm{C}$ na longitude de $42^{\circ} 30^{\prime} \mathrm{W}$; este ponto permaneceu estacionário durante um intervalo de tempo de aproximadamente trinta e duas horas. 


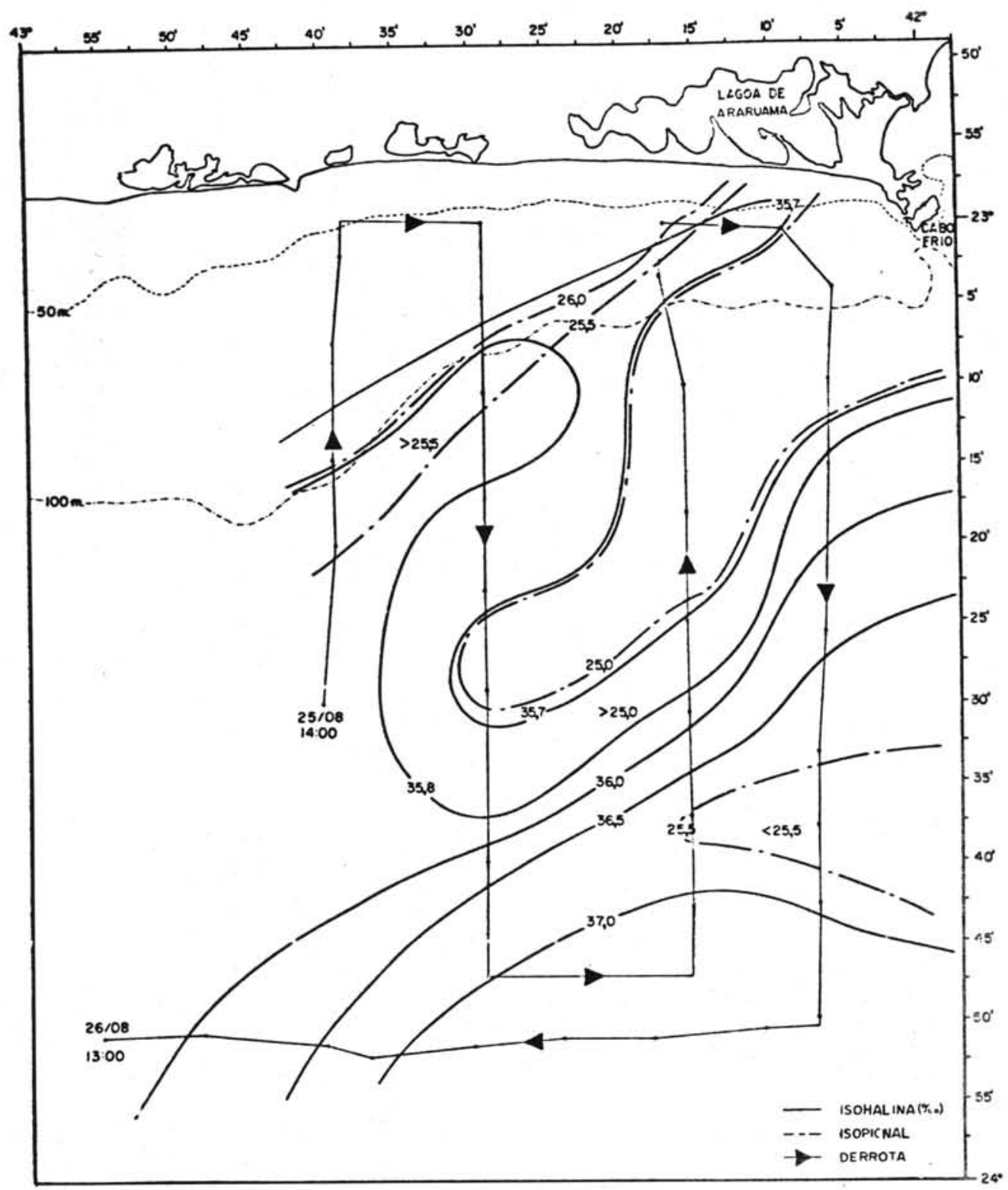

Fig. 25 - Distribuição da salinidade e de Sigma-t na superfície do mar para - 7 ? período $(25 / 08 / 71$ a $26 / 08 / 71)$.

Com relação às derrotas dos registros 1 e 2, observa-se que, à medida que caminhamos para a direção oeste, as temperaturas aumentam, enquanto que para as derrotas dos registros 3 e 4 se observa o contrário.

Os ventos predominantes para este período (20 a 23 de agosto) são $\mathrm{N}$ e NNE (Figs 5-6). 


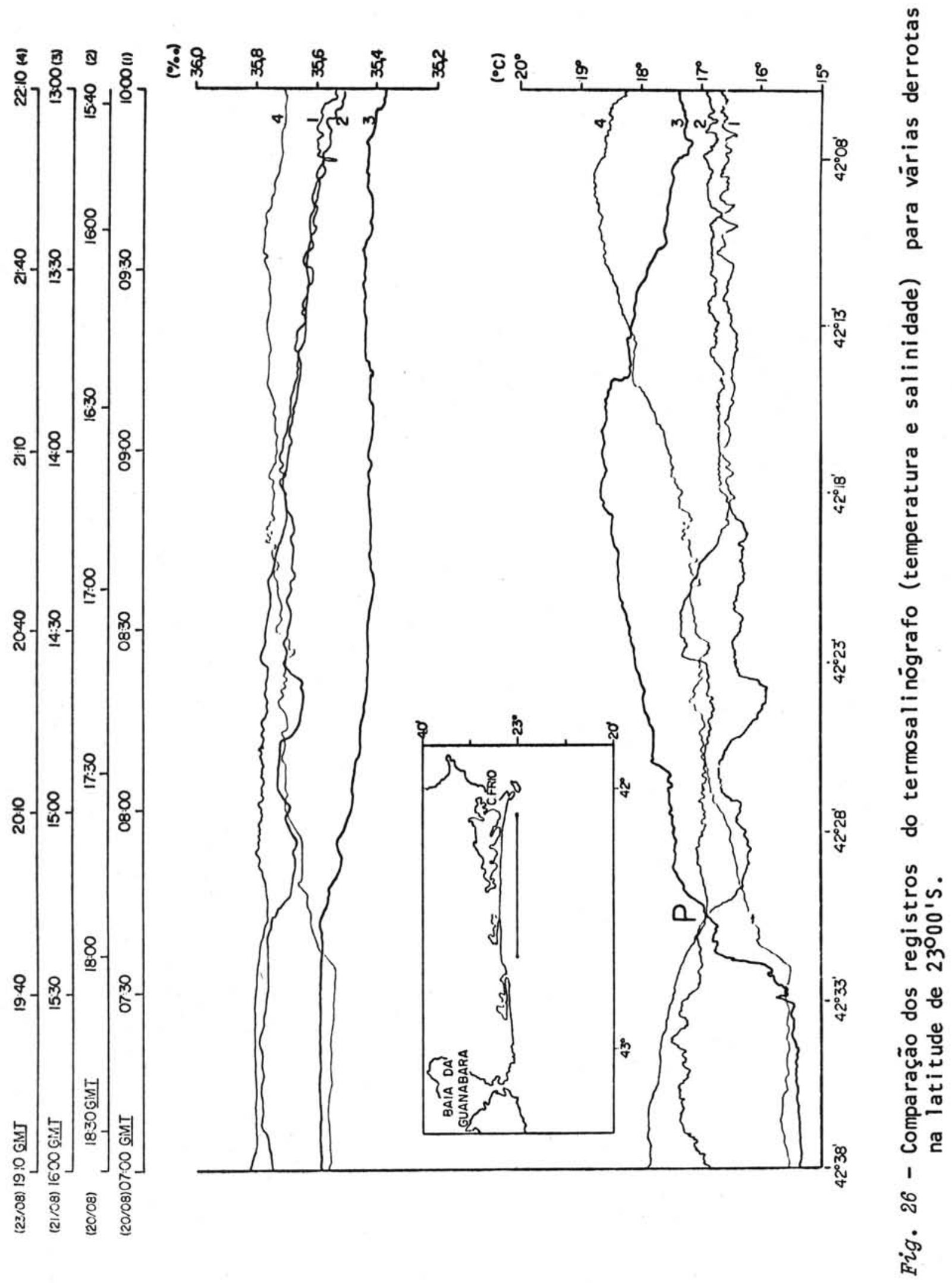


As Figuras 27-28 para os dias 21 e 23 de agosto, respectivamente, são secções verticais paralelas à costa, que complementam as observações de superfície (reg. 3 e 4, Fig. 26).
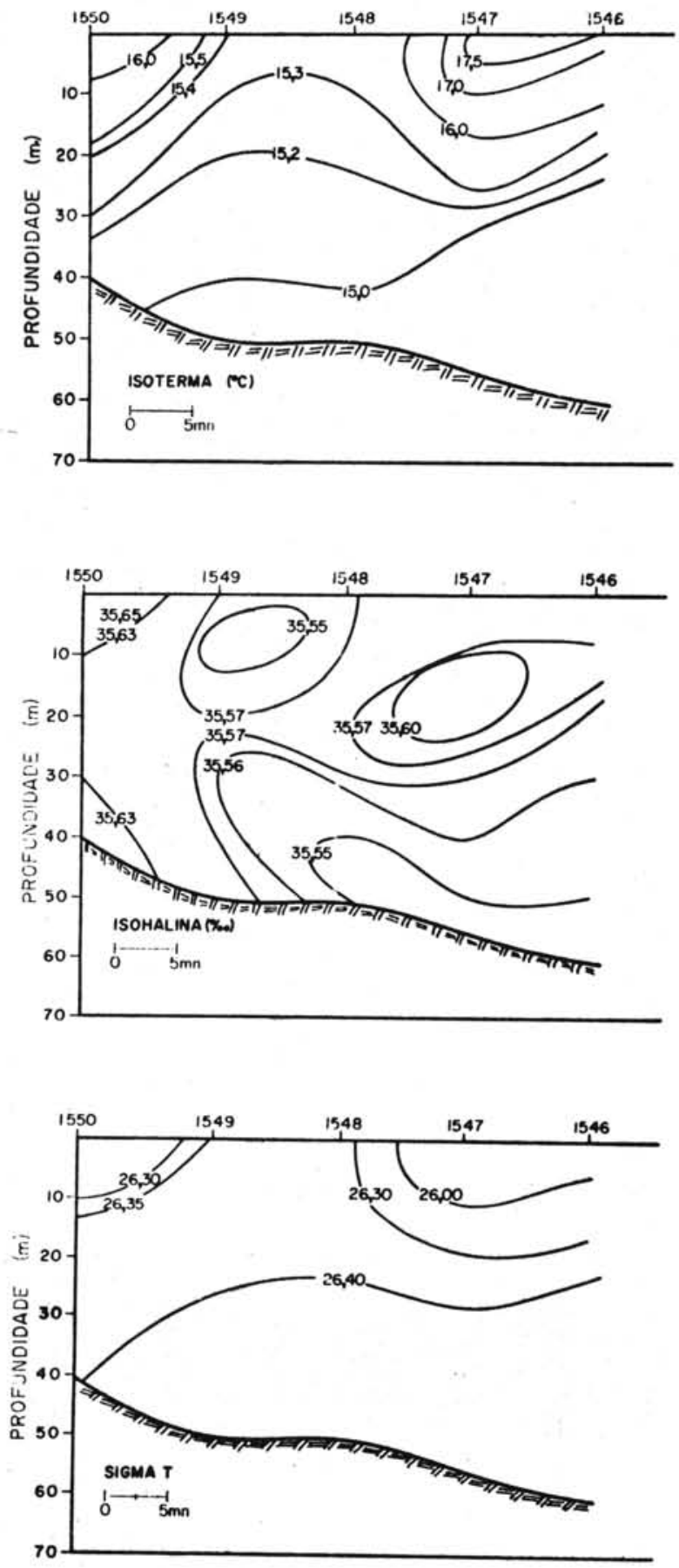

Fig. 27 - Secções verticais (temperatura, salinidade e Sigma-t) na latitude de $23^{\circ} 00^{\prime} \mathrm{s}$, obtida com os dados das estações hidrogrä́ficas. $(21 / 08 / 71)$. 

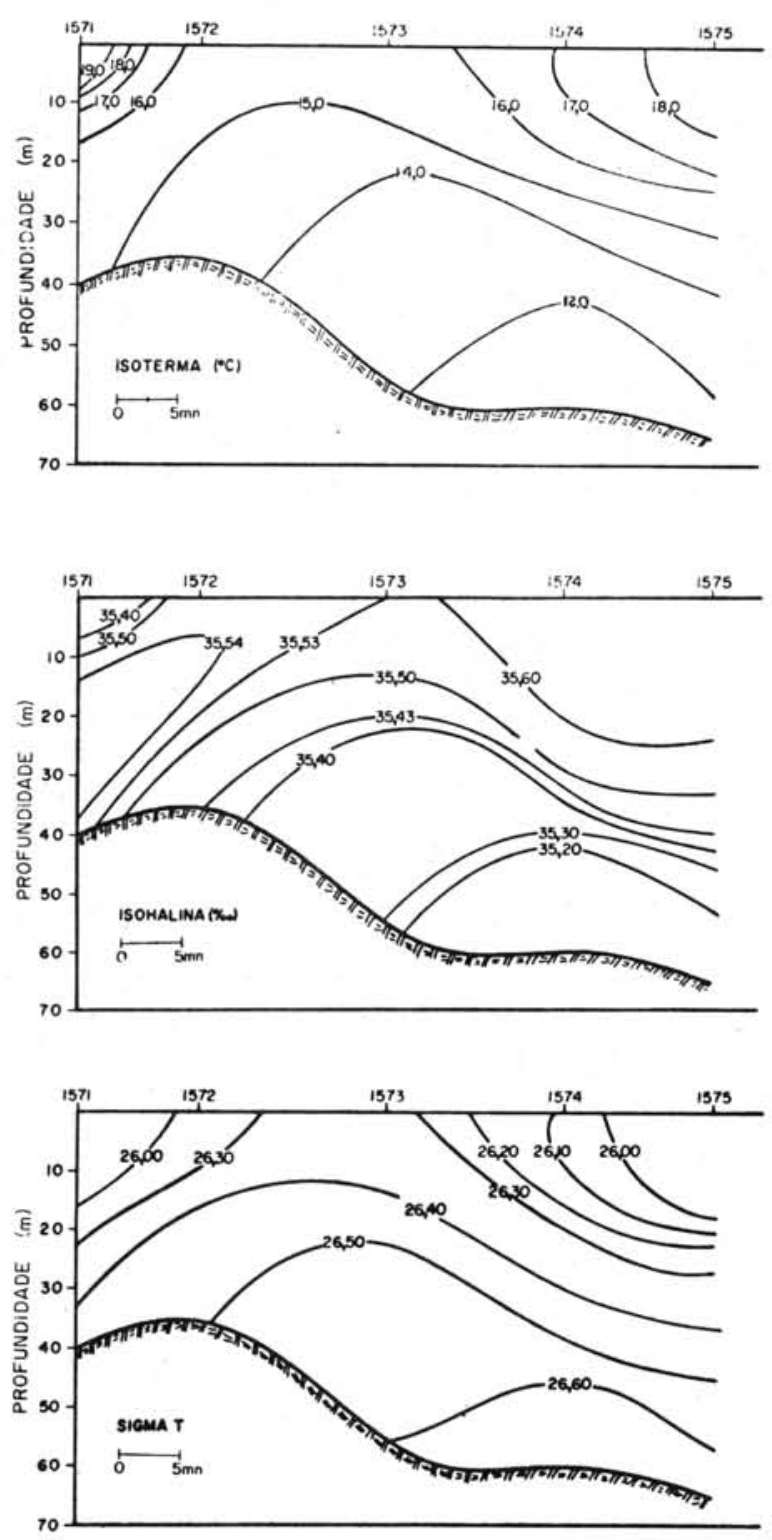

Fig. 28 - Secções verticais (temperatura, salinidade e sigma-t) na latitude de $23^{\circ} 00^{\prime} \mathrm{s}$, obtida com os dados das estações hidrogrä́icas. $(23 / 08 / 71)$.

A comparação dessas Figuras indica a ocorrência de movimentos ascendentes, com ressurgimento de águas entre as estações 1572 e 1574. A continuidade desses movimentos, evidenciada pelas variações de temperatura e salinidade na superfície, é confirmada agora pelas variações dessas propriedades na seç̧ão vertical. Como se observa, hā um decréscimo de temperatura de 15,0 para $13,0^{\circ} \mathrm{C}$ e de salinidade de 35,55 para $35,20^{\circ} \%$ nas proximidades do 
fundo da plataforma continenta1. Este decréscimo, indica um fluxo de água de origem subtropical em direção à costa, cuja influência, graças aos movimentos ascendentes, se observa nas camadas superiores.

0 tempo decorrido entre as estações dos dias 21 e 23 de agosto foi de, aproximadamente, quarenta e oito horas. Tomando por referência a isopicnal $\sigma_{\mathrm{T}} \approx 26,40$, que está a uma profundidade de $23 \mathrm{~m}$ no dia 21 de agosto, entre as estações 1548 e 1549, após quarenta e oito horas, a mesma isopicnal, correspondente ao mesmo local entre as estações 1572 e 1573, jā se encontra a uma profundidade de $11 \mathrm{~m}$.

Essa elevação da isopicnal de $\sigma_{\mathrm{T}}=26,40$, permite estimar a velocidade do movimento ascendente em cerca de $2,50 \times 10^{-1} \mathrm{~m} /$ hora.

Smith, Pattullo \& Lane (1966), encontraram valores experimentais para movimentos ascendentes de uma isopicnal, na costa do Oregon, com extremos de $2,52 \times 10^{-1} \mathrm{~m} /$ hora junto à costa e de $7,20 \times 10^{-3} \mathrm{~m} /$ hora para as estações mais profundas.

Uma velocidade do movimento ascendente de $1,79 \times 10^{-1} \mathrm{~m} /$ hora, foi determinada para Cabo Frio por Almeida \& Azevedo (1971) através de um modêlo matemático para ressurgência.

COMPARAÇÃO DE UMA FOTOGRAFIA DE SATÉLITE COM AS DISTRIBUIÇÕES DE TEMPERATURA NA SUPERFICIE

Durante o período de observações experimentais, não houve cobertura de fotografias de satélite para a região de Cabo Frio e, conseqüentemente, utilizou-se a fotografia do dia 27 de julho de 1973, obtido pelo satélite ERTS (Fig. 29), que se julga ser uma fotografia representativa para as nossas observações.

Pode-se notar nessa fotografia um vento de direção $\mathrm{NE}$, identificada pela fumaça expelida peḷ Companhia Nacional de Ālcalis e, também, uma faixa bem delimitada com nuvens.

De acordo com Soules (1970), pode-se identificar o conjunto de nuvens da Figura 29 como sendo do tipo cúmulos. Levando-se em conta a escala da foto, 
pode-se estimar a extensão de cada nuvem em cerca de $2 \mathrm{~km}$, com um espaçamento entre elas de 4 a $5 \mathrm{~km}$. Como é sabido (Blair, 1964), o processo de formação desse tipo de nuvens é o da "convecção penetrativa", que se caracteriza por movimentos ascendentes, quando certas porções do ar de baixo tornam-se mais aquecidas. Portanto, pode-se concliuir que, na região oceânica onde essas nuvens se formaram, a temperatura da água do mar era maior do que a temperatura do ar. O contrārio deve ocorrer na região costeira à oeste de Cabo Frio, em decorrência da inexistência de nuvens.

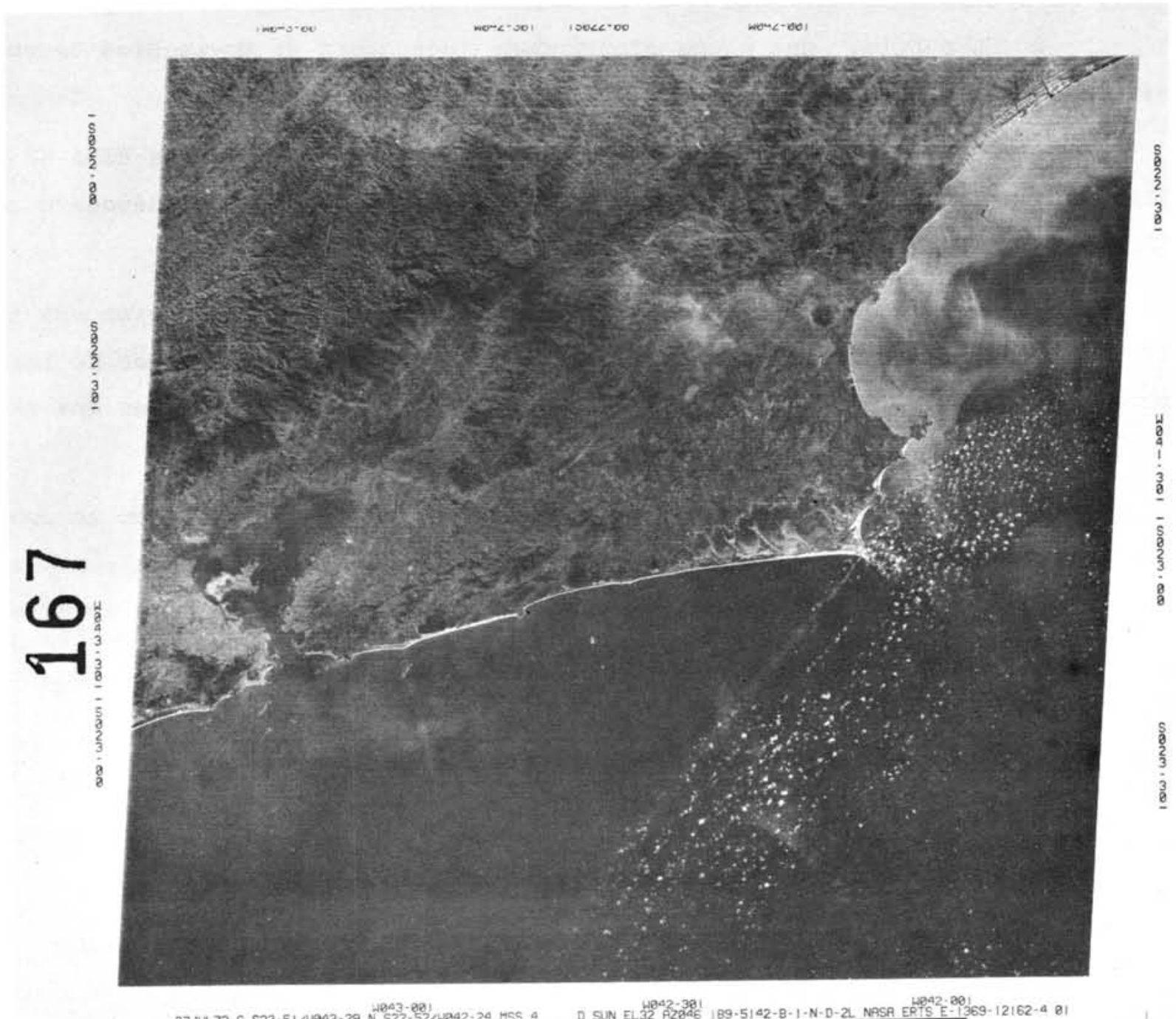

Fig. 29 - Foto obtida pelo satêlite ERTS para o dia 27/07/73, mostrando a delimitação de formação de nuvens do tipo cúmulos com vento de NE. 
Bolm Inst. oceanogr., S Paulo, 25, 1976

A Figura 30 mostra novamente essas nuvens, juntamente com as distribuições de temperaturas na superfície obtidas em agosto de 1971. Apesar de não serem da mesma época, pode-se dizer que a direção dos ventos que sopraram em ambas as épocas era a mesma.

Prosseguindo na comparação da superfície termal, ficou evidente a não formação de nuvens, como mostra a fotografia por satélite na região oeste de Cabo Frio, devido à temperaturas da superfície do mar menores do que a do ar.

Tudo indica, portanto, que as fotos do satélite ERTS podem ser utilizadas para atestar a ocorrência de anomalias na distribuição da temperatura a oeste de Cabo Frio, que é uma propriedade indicadora de movimentos ascendentes da água do mar.

Meneely (1974), usando imagens dos satélites meteorológicos ESSA 9 e NOAA-2, associou a formação de um sistema particular de nuvens/nevoeiro ao fenômeno da ressurgência.

Entretanto, de acordo com Calheiros et al. (1971), pequenas formações de nuvens, (que poderiam proporcionar com maior exatidão a comprovação de tais fenômenos que são de carāter local), não são observáveis nas imagens dos referidos satélites, por se tratarem de imagens em escala grande.

Assim, no presente trabalho, a correlação da imagem do ERTS com as anomalias de temperatura foi verificada através da presença de nuvens cúmulos, cujas proporções são ideais para a verificação de fenômenos em escala média.

\section{CONCLUSÕES}

A anālise das medições experimentais permite as seguintes conclusões:

1 - As anomalias da temperatura e da salinidade na superfície do mar da região em estudo, indicadas pelo aparecimento de núcleos isolados de mínimos de temperatura $\left(\mathrm{T} \cong 17,0^{\circ} \mathrm{C}\right.$ ) associados à salinidade de $35,8^{\circ} \%$, que caracterizam águas de origem subtropical, foram observadas aproximadamente quarenta e oito horas após a mudança da direção do vento, quando este passou a soprar de NE e NNE, com uma velocidade média horária máxima de $8 \mathrm{~m} / \mathrm{s}$. 


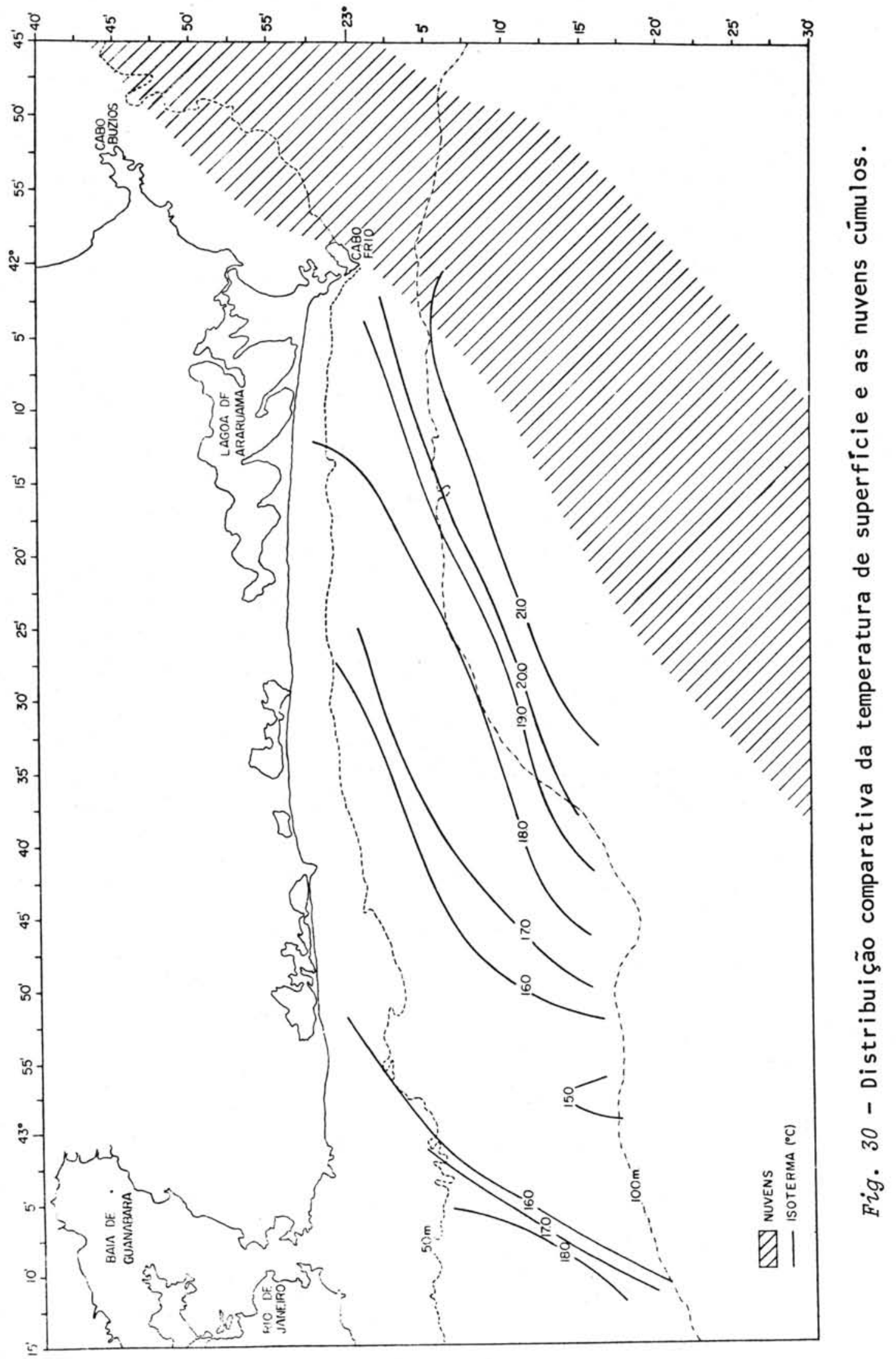


2 - A frente térmica, inicialmente delimitando o mínimo de temperatura, passa a se orientar na direção SW, após decorrido um intervalo de tempo de, aproximadamente, setenta e duas horas. Esta frente térmica atinge o seu estado quase-estacionário após o 59 período de observações, ocasião em que o mínimo de temperatura $\left(\mathrm{T} \cong 15,0^{\circ} \mathrm{C}\right.$ ) encontra-se associado à salinidade entre 35,5 e $35,6^{\circ} / 00$.

3 - Após cento e quarenta e oito horas do início das observações, a configuração das isotermas a $25 \mathrm{~m}$ de profundidade è muito semelhante à da superfície, isto é, tendem a se orientar tambēm na direção SW. Fica, portanto, evidenciado que a influência dos processos advectivos e difusivos, que se restringiam à camada superficial, è também observado nessa profundidade após decorrido esse intervalo de tempo.

4 - Com relação ao deslocamento vertical da isopicnal de sigma-t $=26,40$, estimou-se uma velocidade do movimento ascendente nas proximidades da costa em $2,50 \times 10^{-1} \mathrm{~m} /$ hora, sendo o transporte deste movimento vertical o responsável pelo aparecimento das anomalias observadas na superfície.

5 - Esta região é por alguns considerada de transição para organismos marinhos (Tommasi, 1973), devido à zona frontal térmica, a qual, para se manter, depende da constância na direção do vento. Como na região, os ventos não permanecem na mesma direção por muito tempo, é pouco provável a existência de uma barreira biológica eficiente.

6 - Os cúmulos gerados por "convecção penetrante", com limites bem definidos na direção SW, e facilmente identificados nas fotografias obtidas pelo satélite ERTS, podem se constituir numa boa indicação da ocorrência de anomalias na distribuição da temperatura a oeste de Cabo Frio, provocadas por movimentos ascendentes de água do mar.

\section{RESUMO}

Um aspecto importante a ser apontado no presente trabalho é o fato de se ter acompanhado de um modo ininterrupto, durante 10 dias, as anomalias nas 
distribuições das propriedades físicas da ägua do mar. Os resultados experimentais obtidos na região costeira a oeste de Cabo Frio durante esse período mostraram a preponderância dos processos advectivos e difusivos que alteram a distribuição da temperatura e da salinidade na superfície do mar.

Essa anomalia pode ser indicada por nuvens do tipo cúmulos formada por convecção penetrante, fato verificável pela comparação dos dados térmicos de superfície, com fotografias obtidas pelo satélite ERTS.

\section{AGRADECIMENTOS}

Ao Dr. Luiz Bruner de Miranda apresento os meus melhores agradecimentos pela orientação desta dissertação e pelo incentivo para a sua realização.

Ao Vice-Almirante Alberto dos Santos Franco, então diretor-geral do Instituto Oceanogräfico da Universidade de São Paulo, ao Dr. Fernando de Mendonça, diretor-geral do Instituto de Pesquisas Espaciais, São Josē dos Campos, ao Vice-Almirante Paulo Gitahy de Alencastro, diretor da Diretoria de Hidrografia e Navegação, pelas facilidades concedidas na participação do projeto SEREMAR e na utilização dos dados.

Sou especialmente grato ao Eng. Argeo Magliocca pelo apoio que me deu, desde o início das minhas atividades no Instituto Oceanogrāfico da USP, e à sua equipe pela colaboração na determinação da salinidade em laboratório.

Ao Prof. Dr. Carlos Eduardo de Almeida, ao Prof. Dr. Giorgio Moscati e ao Dr. Paulo César Leone, pela colaboração na implantação do curso de PósGraduação na ārea de Oceanografia Física.

Ao Dr. Luiz Herrera, professor visitante sob os auspícios da OEA, junto ao Programa Multinacional de Ciências do Mar, por suas valiosas sugestões.

Ao Dr. Paulo César Leone, cujos ensinamentos no campo da Hidrodinâmica Aplicada foram utilizados neste trabalho.

Ao coordenador do projeto SEREMAR, M.Sc. Affonso da Silveira Mascarenhas $\mathrm{Jr}$., Bach. Renato Herz e ao Sr. Paulo Domingo Cordaro nas interpretações das imagens do satélite ERTS. 
Ao Dr. Norman J. Rock, pela sua participação e orientação durante as medições experimentais e ao M.Sc. Sérgio Romano Signorini pela colaboração na instalação e teste do termosalinógrafo.

$\bar{A}$ Divisão de Informação e Documentação Científica do IOUSP, na pessoa de sua diretora srta. Lucy Teixeira, por todo o auxílio prestado. Ao Setor de Matemática Aplicada (SEMA) do Instituto de Física da USP pelos processamentos de dados e à Companhia Nacional de Ālcalis, Cabo Frio, pelo fornecimento dos dados horários de ventos da sua estação meteorológica.

Ao Sr. Edison Hidalgo e Sr. Marco Montalban pelos desenhos, gráficios e montagens.

Ao Comandante Adilson Luiz Gama e oficiais do N/Oc. "Prof. W. Besnard" pela colaboração nos trabalhos de campo.

Enfim a todos aqueles que, direta ou indiretamente, colaboraram na elaboração desta dissertação, os meus melhores agradecimentos.

\section{B IBLIOGRAFI A}

ALLARD, P. 1955. Anomalies dans les temperatures de 1'eau de mer observées au Cabo Frio au Brésil. Bull. Inf. Com. cent. Océanogr. Étude Côtes, 7(2): 58-63.

ALMEIDA, E. G. \& AZEVEDO, M. A. L. 1971a. Comparison of remote sensing data with a mathematical model of upwelling at Cabo Frio. United Nations Panel Meeting on the Establishment and Implementation of Research Programmes in Remote Sensing, Rep. 12/ONU/INPE. INPE, Rep. LAFE, 176, 5:part A, 1-13.

1iminary ; MASCARENHAS JR., A. da S. \& IKEDA, Y. I 1971b. PrePanel Meeting on the Establishment and Implementation of Research Programmes in Remote Sensing, Rep. 14/ONU/INPE. INPE, Rep. LAFE, 176, 5:1-73.

BLAIR, T. A. 1964. Meteorologia. Rio de Janeiro, Livro Técnico, $\mathrm{xvi}+406 \mathrm{p}$.

BÖHNECKE, G. 1936. Temperature, Salzgehalt und Dicht an der Oberfläche des Atlantischen Ozeans. Wiss. Ergebn. dt atlant. Exped. "Meteor", 5, Atlas. 
BOWDEN, K. F. 1962. Turbulence. In: HILL, M. N., ed.- The sea: ideas and observations on progress in the study of the seas. New York, John Wiley, vol. 1, p. 802-825.

BRASIL. DIRETORIA DE HIDROGRAFIA E NAVEGAÇÃO 1960. Estudo das condições oceanográficas sobre a plataforma continenta1, entre Cabo Frio e Vitōria, durante o outono (abri1-maio). Pub1. DG-06-X:1-28.

CALHEIROS, R. C.; MOURA, A. D. \& SANTOS, R. P. dos 1971. Curso de Treinamento para operadores de Estações APT. INPE, Rep. LAFE, 167, 2:116-215.

DEFANT, A. 1961. Physical oceanography. Oxford, Pergamon Press, vo1. 1 .

EMILSSON, I. 1961. The shelf and coastal waters of southern Brasil. Bolm Inst. oceanogr., S Paulo, 11(2):101-112.

IKEDA, Y. 1971. Relatōrio sobre a instalação do termosalinógrafo e seu funcionamento no N/Oc. "Prof. W. Besnard". (Datilografado).

; MIRANDA, L. B. de \& ROCK, N. J. 1971. Observations on stages of upwelling in the region of Cabo Frio (Brazil) as conducted by continuous surface temperatures and salinity measurements. United Nations Pane1 Meeting on the Establishment and Implementation of Research Programmes in Remote Sensing, Rep. 14/ONU/INPE. INPE, Rep. LAFE, $176,5: 74-97$.

JAPÃO, MINISTRY OF AGRICULTURE AND FORESTRY. FISHING AGENCY. 1963. Survey report on the Brazilian fishing grounds. Rio de Janeiro, $388 \mathrm{p}$.

JOINT PANEL ON OCEANOGRAPHIC TABLES AND STANDARDS. 1966. Second report of the Joint Pane1 on Oceanographic Tables and Standards. UNESCO Tech. Pap. mar. Sci., (4):1-9.

LA FOND, E.C. 1951. Processing oceanographic data. Pub1s U.S. hydrogr. Off., (614): $1-114$.

MAGLIOCCA, A.; MIRANDA, L. B. de \& SIGNORINI, S. R. On the upwelling occurrence in the region of Cabo Frio (Brazil) during February 1971. (No prelo).

MASCARENHAS JR., A. S.; MIRANDA, L. B. de \& ROCK, N. J. 1971a. A study of the oceanographic conditions in the region of Cabo Frio. In: COSTLOW JR., J.D., ed.- Fertility of the sea. New York, Gordon \& Breach, vol. 1, p. $285-308$. in Remote sensing, Rep. 12/ONU/INPE. INPE, Rep. LAFE, 176, 5:part B, 1-38. 
MATSUURA, Y. 1971. A study of the life history of Brazilian sardines Sardineila aurita. Part 1. Distribution and abundance of sardine eggs in the region of Ilha Grande, Rio de Janeiro. Bolm Inst. oceanogr., S Paulo, 20(1):33-60.

MENEELY, J. M. 1974. Some satellite observations of coastal upwelling. Coastal Upwelling Ecosystems Analysis (CUEA), a program of the International Decade of Ocean Exploration (IDOE). vol. 3, (2):15-16.

NAN'NITI, T. 1964. Some observed results of oceanic turbulence. In: YoSHIDA, K., ed.- Studies on oceanography. Tokyo, Univ. of Tokyo Press, p. 211-215.

OKUBO, A. 1970. Oceanic mixing. Tech. Rep. Chesapeake Bay Inst., (2) : 1-119.

OWEN, W. M. 1954. Laminar to turbulent flow in a wide open channel. Trans. Am. Soc. civ. Engrs, 119:1157-1164.

ROLL, H. U. 1974. Tópicos de interação ar-mar. Disciplina ministrada no Curso de Pós-Graduação em Oceanografia Física do Instituto Oceanográfico da USP. (Notas de Aulas).

SCHLICHTING, H. 1968. Boundary-1ayer theory. 6ed. Translated by J. Kestin. New York, McGraw-Hi11, 747 p.

SILVA, P. C. M. da \& RODRIGUES, R. F. 1966. Modificações na estrutura vertical das águas sobre a borda da plataforma continental por influência do vento. Notas téc. Inst. Pesq. Mar., (35):1-13.

SMITH, R. L.; PATTUlLO, J. G. \& LANE, R. L. 1966. An investigation of the early stage of upwelling allong the Oregon coast. J. geophys. Res., 71(4):1135-1140.

SOULES, S. D. $\quad$ 1970. Sun glitter viewed from space. Deep Sea Res., $17(1): 191-195$.

STRAUB, L. G.; SILBERMAN, E. \& NELSON, H. C. 1957. Open channel flow at sma11 Reynolds Number. Trans. Am. Soc. civ. Engrs., 123:685-706.

SVERDRUP, H. U.; JOHNSON, M. W. \& FLEMING, R. H. 1942. The oceans; their physics, chemistry, and general biology. New York, Prentice-Ha11, $\mathrm{x}+1087 \mathrm{p}$.

TOMMASI, L. R. 1973 . Biogeografia do Atlântico Sul. Disciplina ministrada no Curso de Pós-Graduação em Oceanografia Biológica do Instituto Oceanográfico da USP (Notas de aulas). 